\title{
¿Sources of Subseasonal Predictability over CONUS during Boreal Summer $\mathscr{O}$
}

\author{
V. Krishnamurthy, ${ }^{\mathrm{a}}$ Jessica MeiXner, ${ }^{\mathrm{b}}$ Lydia Stefanova, ${ }^{\mathrm{c}} \mathrm{JiAnde}$ Wang, ${ }^{\mathrm{c}}$ Denise Worthen, ${ }^{\mathrm{c}}$ \\ Shrinivas MoOrthi, ${ }^{\mathrm{b}}$ Bin Li, ${ }^{\mathrm{c}}$ Travis Sluka, ${ }^{\mathrm{d}}$ AND Cristiana Stan ${ }^{\mathrm{e}}$ \\ ${ }^{\text {a } C e n t e r ~ f o r ~ O c e a n-L a n d-A t m o s p h e r e ~ S t u d i e s, ~ G e o r g e ~ M a s o n ~ U n i v e r s i t y, ~ F a i r f a x, ~ V i r g i n i a ~}$ \\ ${ }^{\mathrm{b}}$ NOAA/NCEP/EMC, College Park, Maryland \\ ${ }^{\mathrm{c}}$ IMSG at NOAA/NCEP/EMC, College Park, Maryland \\ ${ }^{\mathrm{d}}$ Joint Center for Satellite Data Assimilation, Boulder, Colorado \\ ${ }^{\mathrm{e}}$ Department of Atmospheric, Oceanic and Earth Sciences, George Mason University, Fairfax, Virginia
}

(Manuscript received 27 July 2020, in final form 13 January 2021)

\begin{abstract}
The predictability of the Unified Forecast System (UFS) Coupled Model Prototype 2 developed by the National Centers for Environmental Prediction is assessed for the boreal summer over the continental United States (CONUS). The retrospective forecasts of low-level horizontal wind, precipitation and 2-m temperature for 2011-17 are examined to determine the predictability at subseasonal time scale. Using a data-adaptive method, the leading modes of variability are obtained and identified to be related to El Niño-Southern Oscillation (ENSO), intraseasonal oscillation (ISO), and warming trend. In a new approach, the sources of enhanced predictability are identified by examining the forecast errors and correlations in the weekly averages of the leading modes of variability. During the boreal summer, the ISO followed by the trend in UFS are found to provide better predictability in weeks 1-4 compared to the ENSO mode and the total anomaly. The western CONUS seems to have better predictability on weekly time scale in all three modes.
\end{abstract}

KEYWORDS: Climate prediction; Hindcasts; Operational forecasting; Seasonal forecasting; Intraseasonal variability; Oscillations

\section{Introduction}

The prediction of the instantaneous state of the weather system is reliable only up to about 10 days (e.g., ECMWF 2018), mainly because of the limitations imposed by chaos (e.g., Lorenz 1965, 1982) and the instabilities involved. Beyond the weather time scale, the operational prediction centers instead have been providing forecasts of seasonal mean climate (e.g., Saha et al. 2006, 2014; Stockdale et al. 2011). The basis for extended time-averaged predictions comes from the existence of low-frequency planetary waves, atmospheric regimes, and similar phenomena (Lorenz 1984). Even more optimism for climate prediction is based on the influence of slowly varying components such as sea surface temperature (SST), soil moisture, sea ice, etc. in determining the long-term variability of climate (Charney and Shukla 1981). The focus on the prediction of seasonal means is somewhat related to a better prediction of $\mathrm{El}$ Niño-Southern Oscillation (ENSO) and its influence on several regional atmospheres (e.g., Kim et al. 2012).

The importance of seamless prediction of weather and climate has been recognized recently with the emphasis on predictions at subseasonal time scales (National Academies of

๑ Denotes content that is immediately available upon publication as open access.

Supplemental information related to this paper is available at the Journals Online website: https://doi.org/10.1175/JCLI-D-200586.s1.

Corresponding author: Cristiana Stan, cstan@gmu.edu
Science Engineering and Medicine 2016), especially at weeks 3-4. A dominant mode of variability in the tropics is the intraseasonal oscillation (ISO) that manifests as the MaddenJulian oscillation (MJO) and monsoon ISO (MISO) or the boreal summer ISO (BSISO). Since these ISOs are coherent patterns that vary in a nearly regular manner, several forecasting centers have been issuing long-range prediction of the filtered MJO (Gottschalck et al. 2010). A data-driven model showed that the instantaneous state of filtered MISO can be predicted with high accuracy several weeks in advance (Krishnamurthy and Sharma 2017). The extratropics is found to have its own ISOs (Ghil et al. 2018; Stan and Krishnamurthy 2019) as well as teleconnections with the tropical ISOs (Stan et al. 2017).

There has been no satisfactory answer to the fundamental question whether climate is predictable (Lorenz 2006). A more tractable question is whether some aspects of climate in space and time can be predicted, which may lead to identifying the sources of such predictability. Some of the recent effort in climate prediction is focused on the scientific basis and sources of predictability at intraseasonal to seasonal time scales (Robertson and Vitart 2019; Merryfield et al. 2020). The ocean-atmosphere interaction of ENSO and the organized convection in MISO/BSISO and MJO are major sources of slow variability and nearly regular cycles within a season. The motivation for this study stems from the possibility of signals and teleconnections of ENSO and ISOs over the continental United States (CONUS) providing enhanced predictability at subseasonal time scale.

Several studies have investigated the influence of atmospheric regimes, the MJO, and ENSO on the predictability of weather over the United States during the boreal winter. A summary of the studies on the teleconnections between tropics 
and extratropics is provided by Stan et al. (2017). The atmospheric regimes or clusters over the United States during winter seem to be related to or modulated by MJO and ENSO (Robertson and Ghil 1999; Riddle et al. 2013). The forecast skill of winter clusters was found to be limited to two weeks by Vigaud et al. (2018), who further suggested that the relation with MJO and ENSO offers potential for subseasonal predictability. The prediction skill of the wintertime surface temperature over North America was suggested to be better up to three weeks during certain phases of MJO (Rodney et al. 2013) and up to four weeks with information from MJO and ENSO (Johnson et al. 2014). During winter, the North American precipitation distribution shows spatial and temporal interference patterns and modulation due to the combined influence of MJO and ENSO (Arcodia et al. 2020). An analysis of the Climate Forecast System version 2 (Saha et al. 2014) predictions of wintertime atmospheric circulation over North America showed individual winters with better skill up to 30 days although the average skill was limited to 10-15 days (Robertson et al. 2020). While these studies have examined the predictability over North America during the boreal winter, there has been almost no study addressing the prediction during the boreal summer. A recent study (Huang et al. 2019) of the model forecasts, however, indicated boreal summer precipitation to be concentrated over central and southern United States but found the winter predictions to have more skill.

The objective of this study is to assess the predictability of a coupled model over the CONUS during the boreal summer and to identify the sources of predictability at subseasonal time scale. The month-long retrospective predictions of the coupled model generated by the National Centers for Environmental Prediction (NCEP) of the National Oceanic and Atmospheric Administration (NOAA) for the period 2011-17 are used. The sources of predictability are identified by examining the leading space-time modes of variability determined by applying a data-adaptive method. The errors and their growth and the spatial correlation between observations and forecasts in each mode will be studied to assess the predictability of the model in weeks $1-4$ of the prediction.

In section 2, the coupled model and its retrospective forecasts, observed and reanalysis data used, and the method of analysis are described. The errors in the prediction of total anomalies of low-level horizontal wind, precipitation and 2-m temperature are discussed in section 3 . The leading modes of variability are obtained in section 4 and the model's performance in predicting these modes are discussed. Section 5 provides quantitative assessment of predictability through the analysis of forecast errors and correlation analysis and identifies sources of better predictability. A summary and discussion are given in section 6 .

\section{Model, data, and method of analysis}

\section{a. Model}

The model adopted for this study is the Unified Forecast System (UFS) Coupled Model Prototype 2 developed by the NCEP. The version of the UFS is the coupled model with the atmospheric component (FV3GFS) at C384 ( $28 \mathrm{~km})$ resolution, and oceanic (GFDL MOM6 model; Adcroft et al. 2019) and sea ice (Los Alamos CICE5 model) components with a tripolar $0.25^{\circ}$ global grid. The retrospective forecasts of the UFS, covering the period April 2011-December 2017, were generated by the NCEP. The initial conditions for the atmospheric and sea ice models are from the Climate Forecast System Reanalysis data while the ocean model is initialized using the Climate Prediction Center (CPC) Hybrid Global Ocean Data Assimilation System. Each retrospective forecast is 35 days long starting from the first and 15th days of each month. Since this study is focused on the boreal summer, daily values of various variables of forecasts initiated during JuneSeptember (JJAS) are analyzed. There are 56 forecasts for the entire period of analysis accounting for two initial conditions each month for 28 months during JJAS 2011-17. For convenience and brevity, the retrospective forecasts will be referred to simply as forecasts or predictions, hereafter.

\section{b. Data}

Daily precipitation was obtained from CPC unified (CPCU) gauge-based analysis of global daily precipitation (Xie et al. 2010 ) on a $0.5^{\circ} \times 0.5^{\circ}$ grid for the period 2011-17. Since the CPCU data are only on land points, the daily precipitation from the Global Precipitation Climatology Project (GPCP; Huffman et al. 2001) version 1.2 covering both land and ocean on a $1^{\circ} \times 1^{\circ}$ grid is used for the period 1997-2017. From the $\mathrm{CPC}$, the analysis of daily maximum and minimum temperature at $2 \mathrm{~m}$ on a $0.5^{\circ} \times 0.5^{\circ}$ grid over CONUS was also obtained for the period 2011-17. The daily average temperature was calculated as the average of daily maximum and minimum temperatures. The daily mean zonal velocity $u$ and meridional velocity $v$ on $\mathrm{T} 255$ horizontal grid $\left(\sim 0.703^{\circ}\right.$ resolution) at $850 \mathrm{hPa}$ from the European Centre for Medium-Range Weather Forecasts (ECMWF) interim reanalysis (ERA-Interim, herein ERAI; Dee et al. 2011) are used for the period 1979-2011. The daily mean sea surface temperature on a $0.25^{\circ} \times 0.25^{\circ}$ grid for the period 1982-2017 was provided by the Optimally Interpolated SST version 2 (OISST2) dataset developed by NOAA (Reynolds et al. 2007). For convenience, both the observed and reanalysis data will be referred to as observed data. For both the observed and model data, the daily climatological mean was computed as the average of the calendar day over the period of the data. Although the averaging period is short for the model data, other methods such as using harmonics are not suitable because each forecast is only 35 days long. The daily anomalies are computed by subtracting the climatological mean from the daily values of the variable under consideration. Similarly, the weekly means and anomalies are computed by averaging the daily means and anomalies, respectively, over the week under consideration.

\section{c. Method of analysis}

The main method of analysis is the multichannel singular spectrum analysis (MSSA), also called extended EOF, to extract the space-time modes of climate variability over the American region. This data-adaptive method, which extracts both temporal and spatial patterns, yields trends, persistent modes, and nonlinear oscillations when applied to time series of spatial maps (Ghil et al. 2002). A given time series $X(t)$ at $L$ spatial grid points at time $t=1, \ldots, N$ is transformed into $M$ lagged copies, each of length $N-M+1$, to construct a grand 
lagged covariance matrix $\mathbf{C}$. By diagonalizing $\mathbf{C}$, the spacetime empirical orthogonal functions (ST-EOFs) are obtained as eigenvectors, each consisting of $M$ lags of $L$-dimensional map. The $L M$ eigenvalues explain the variance while the space-time principal components (ST-PCs), each of length $N-M+1$, are obtained by projecting the ST-EOFs on the original lagged data. The reconstructed component (RC) of a specific eigenmode is computed by combining the corresponding ST-EOF and ST-PC using the formula given by Ghil et al. (2002). The RCs possess the same spatial and temporal dimensions and the phase of the original time series, and their sum is equal to the original time series. An oscillation, which is not strictly periodic, appears as a pair of eigenmodes with almost degenerate eigenvalues and with their ST-EOFs and STPCs in quadrature (Plaut and Vautard 1994). The statistical significance of the eigenmodes is determined by following a Monte Carlo test against signals from red noise (Allen and Robertson 1996; Allen and Smith 1996).

\section{Errors in prediction}

The aim of this study is to assess the predictability of possible sources or modes of variability that provide better predictions at subseasonal time scale, specifically at weeks $1-4$ during the boreal summer. Before identifying such sources, this section first examines the errors in the model's prediction of the total anomalies for an understanding of the general forecast skill of the model.

The root-mean-square (RMS) errors in the total anomalies of horizontal wind at $850 \mathrm{hPa}$, precipitation, and 2-m temperature in week 1-4 predictions are examined. For each variable, the weekly anomalies for the first four weeks of each prediction by the model (i.e., starting from the first and 15th of each month) and the corresponding weekly anomalies of observation were computed. The RMS error for the first four weeks were computed as the average of the difference between the model prediction and observation over all the 56 forecasts at each grid point over CONUS during JJAS of 2011-17.

The RMS errors in the zonal and meridional wind at $850 \mathrm{hPa}$ are shown in Figs. 1a and 1b, respectively, for week 1-4 predictions. For both the zonal and horizontal wind, the error growth is lower in the western states and generally higher to the east from week 1 to 4 . In the zonal wind (Fig. 1a), errors reach a maximum of about $2 \mathrm{~m} \mathrm{~s}^{-1}$ during week 2 and do not change much during weeks 3-4 in the western states. However, over the eastern half of the United States, errors grow from week to week reaching a maximum of about $4 \mathrm{~m} \mathrm{~s}^{-1}$, with large errors along the East Coast, mid-Atlantic, and part of the Midwest. In the meridional wind (Fig. 1b), errors do not grow much after week 2 over the western states with a maximum of about $2 \mathrm{~m} \mathrm{~s}^{-1}$, but they grow steadily over the Midwest and the states to its south, reaching a maximum of $4 \mathrm{~m} \mathrm{~s}^{-1}$ over a large part. The errors in the eastern part grow up to about $2 \mathrm{~m} \mathrm{~s}^{-1}$ in week 2 and do not change much during weeks 3-4.

The RMS errors in precipitation and 2-m temperature for weeks 1-4, shown in Fig. 2, reveal that there are differences in the spatial structure between the two fields while the forecast errors grow. The errors in precipitation (Fig. 2a) are also larger in the eastern half of the United States for all the weeks while the western states show very small growth with maximum error of about $2 \mathrm{~mm}$ day $^{-1}$. The errors in the eastern part grow from week 1 to 3 with the largest errors of up to about $5 \mathrm{~mm}^{\text {day }}{ }^{-1}$ occurring in the southern and eastern coastal states. The errors in week 4 remain somewhat the same as in week 3 . The errors in 2-m temperature are nearly uniform around $1 \mathrm{~K}$ over the CONUS in week 1 and grow steadily from week 2 to 4 . The errors grow mostly over the entire northern part while those in the southern part are under $2 \mathrm{~K}$. Large errors reaching up to $4 \mathrm{~K}$ in weeks 3 and 4 cover the Midwest and states in the western and eastern parts. The errors in Fig. 2 reveal that there is considerable difference between the precipitation and temperature in the magnitude and the location of the growth. The errors described in this section correspond to all time scales and all the phenomena over the CONUS and reveal limited predictability at subseasonal time scale. In the next two sections, the predictability at subseasonal time scale and some possible sources are discussed.

\section{Modes of variability}

The approach used in this study to identify the possible sources of predictability in the subseasonal time scale is to decompose the total anomaly into modes of variability in both space and time. Such space-time patterns or modes are extracted by applying MSSA (Ghil et al. 2002), described in section 2 , on daily anomalies of suitable variables. The domain selected for performing MSSA is $180^{\circ}-15^{\circ} \mathrm{W}, 20^{\circ} \mathrm{S}-41^{\circ} \mathrm{N}$, which includes oceanic and land area around CONUS so that the influences of different phenomena such as ENSO and ISO are represented. The MSSA was applied on daily anomalies of $u$, $v$ at $850 \mathrm{hPa}$ from ERAI for the period 1 June-30 September of 1979-2017 using lags of 0-60 days at a 1-day interval. The choice of the variables and the period of analysis was based on the need to obtain modes of variability that are statistically significant and cover the oceanic region to properly capture dynamics of the region. Other variables that were considered, such as precipitation, have several deficiencies such as lack of coverage over ocean and nonavailability for either long periods or on daily time scale. The length of the lag window allows the resolution of intraseasonal oscillations. The MSSA was carried out by including $u$ and $v$ together. To avoid the dominance of the variance by either of the two variables, $u$ and $v$ were divided by normalization constants before applying MSSA, and the components of the resulting eigenvectors were later multiplied by the corresponding normalization constants. The normalization constant for each variable was computed as the RMS of its value over all the grid points and over the entire period. The MSSA has been extensively used by previous studies to obtain space-time patterns of intraseasonal oscillations, seasonally persisting modes, and trends (e.g., Krishnamurthy and Shukla 2007).

\section{a. Leading modes of horizontal wind in observation}

The MSSA of the horizontal wind yielded eigenvectors, which are the ST-EOFs, each with 61 lagged spatial maps, and the corresponding ST-PCs. A preliminary examination showed 


\section{RMS error in total anomaly}

(a) $850 \mathrm{hPa} \mathrm{u}$
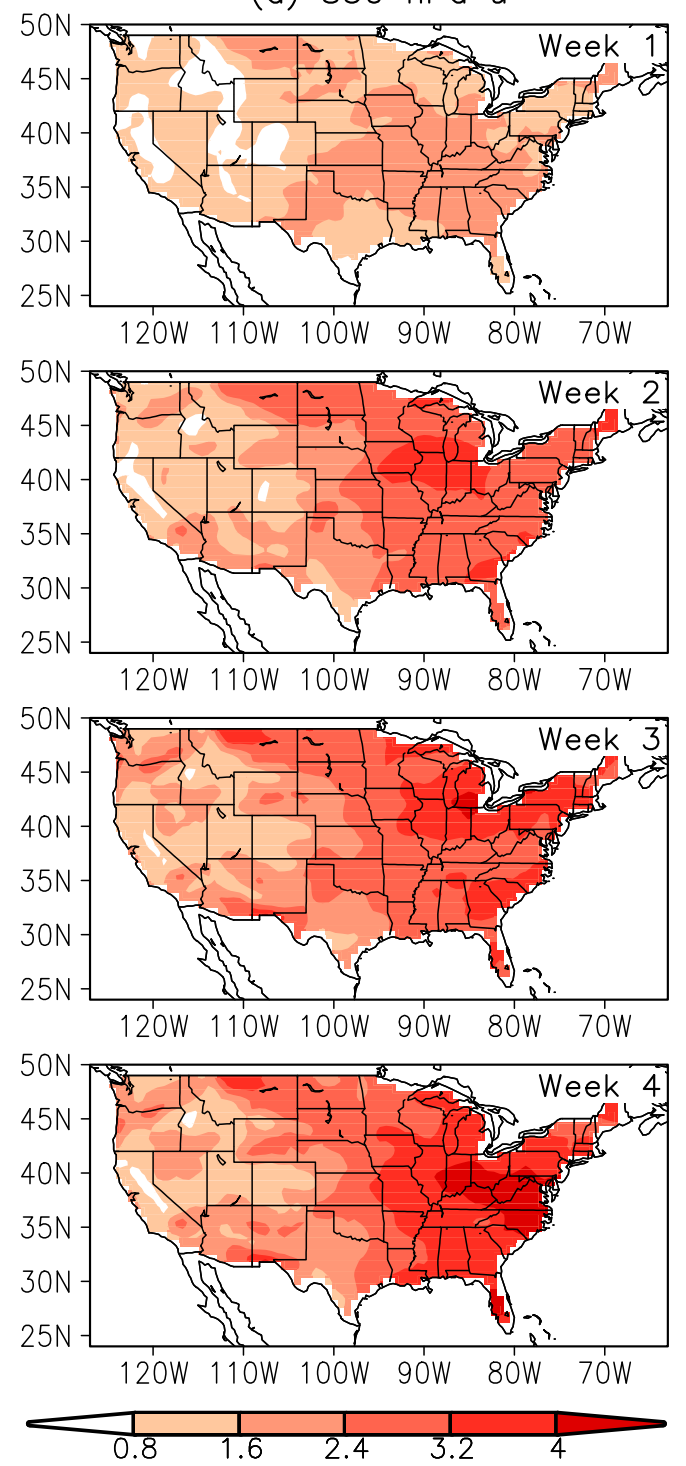

(b) $850 \mathrm{hPa} \mathrm{r}$
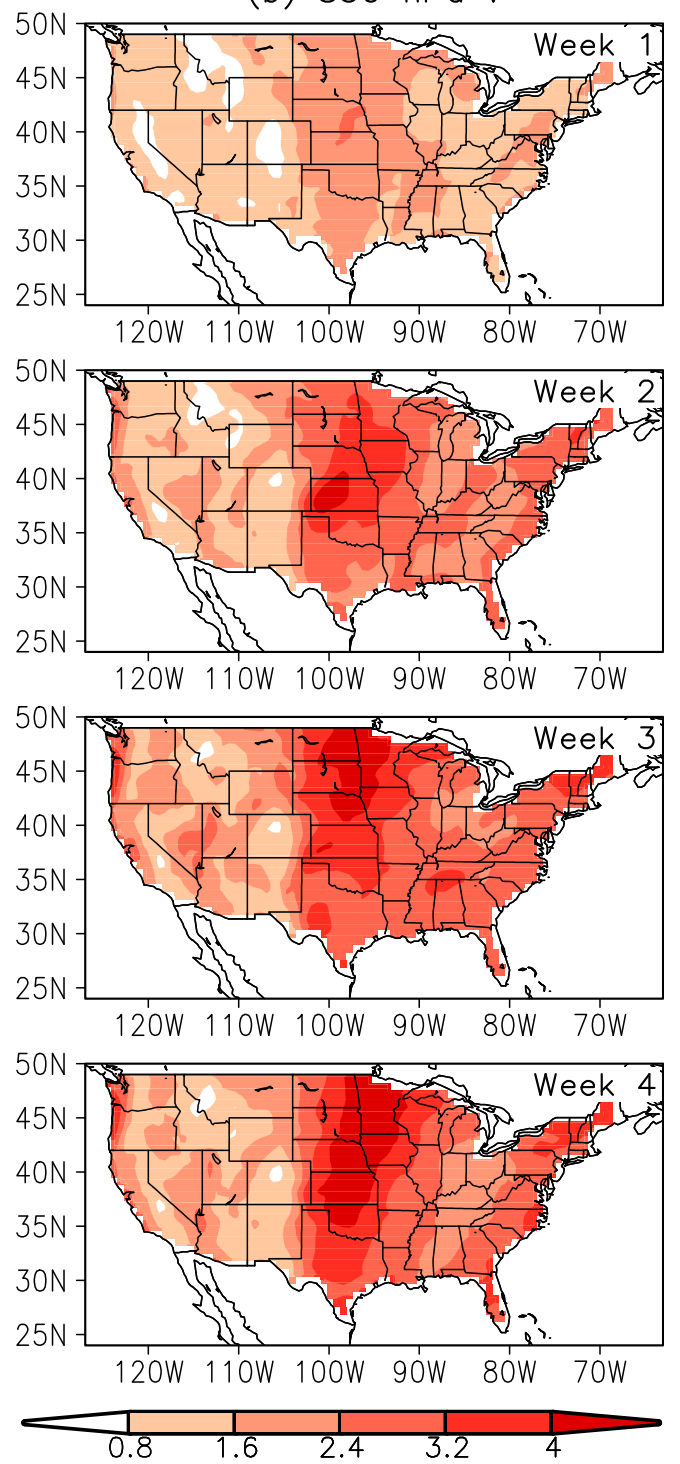

FIG. 1. RMS error of UFS forecasts in the weekly average total anomalies of (a) 850-hPa zonal wind $u\left(\mathrm{~m} \mathrm{~s}^{-1}\right)$ and (b) 850-hPa meridional wind $v\left(\mathrm{~m} \mathrm{~s}^{-1}\right)$ for week $1-4$. The week of the forecast is indicated in the upper right corner of the panel. The RMS error includes all the forecasts during JJAS 2011-17.

that the first four eigenvectors exhibit clearly identifiable spatial patterns in ST-EOFs and distinct intraseasonal and interannual variability in the time series of ST-PCs. These four leading modes are statistically significant above the $5 \%$ level as determined by using the Monte Carlo test against red noise (Allen and Robertson 1996; Allen and Smith 1996). As other eigenmodes are not so well discernable, the rest of the paper will be devoted to the discussion of the leading four eigenmodes.

Eigenmodes 1 and 4 are found to be seasonally persisting modes while eigenmodes 2 and 3 form an oscillatory pair. The eigenvalues of eigenmodes $(2,3)$ are almost degenerate and their ST-EOFs and ST-PCs are in quadrature. For each eigenmode, the corresponding ST-EOFs and ST-PC are combined to obtain the RC, which has the same spatial and temporal dimensions as the original time series. The RC of each eigenmode can be analyzed separately. An EOF analysis was performed separately on each of the first four RCs to obtain their dominant spatial structures and time variability. The first EOF of each RC explains almost all of the variance of the corresponding mode because of its coherent structure. The spectra of the first PC (PC1) of the four RCs are shown in Fig. 3a. The first and fourth RC (RC1 and RC4) show red spectra, indicating persisting non-oscillatory behavior within the season. As stated earlier, the second and third RC (RC2 


\section{RMS error in total anomaly}

(a) Precipitation
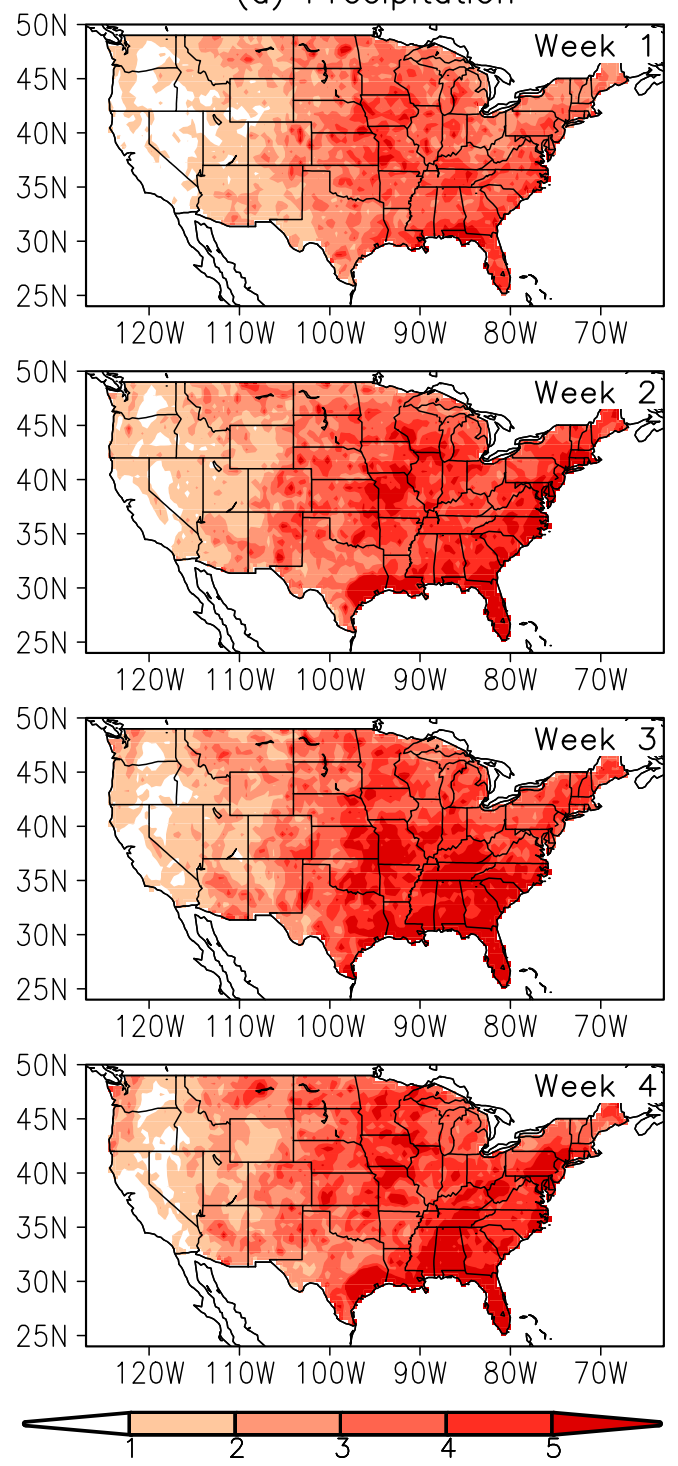

(b) $2 \mathrm{~m}$ Temperature
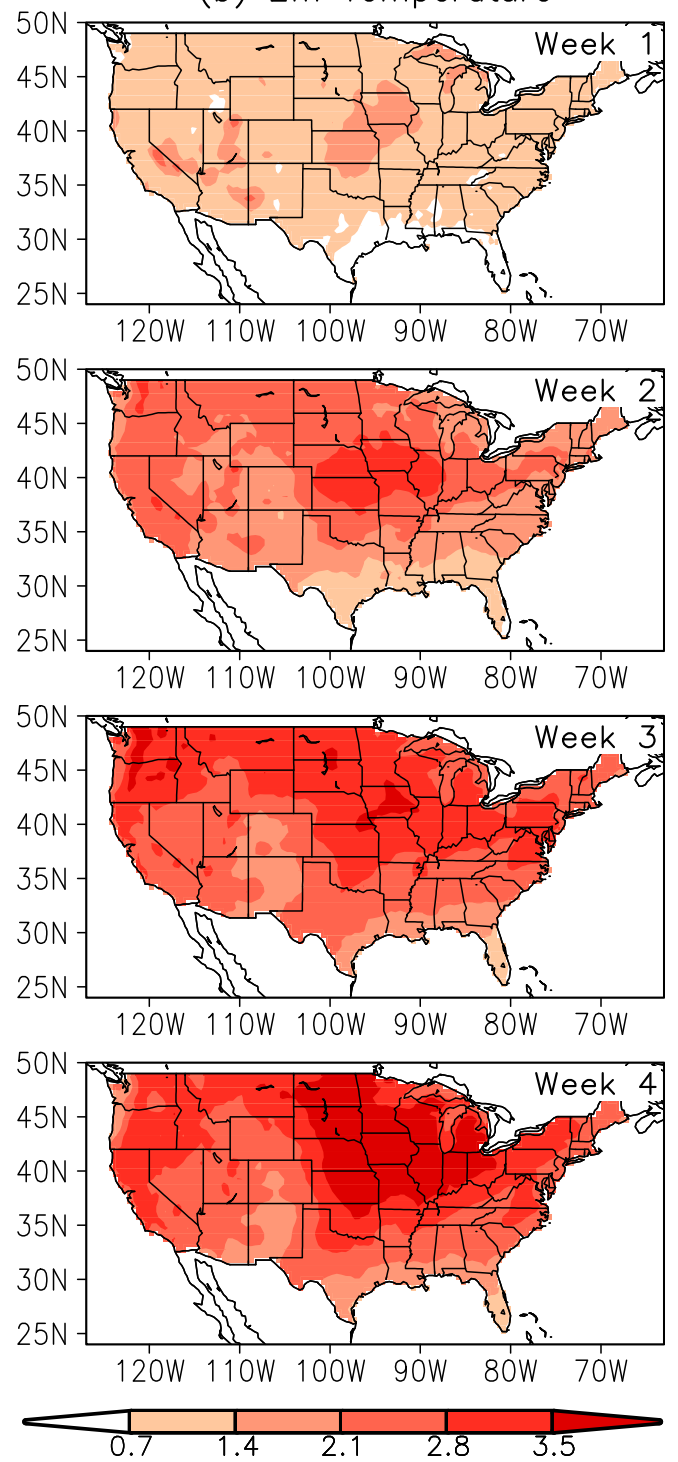

FIG. 2. RMS error of UFS forecasts in the weekly average total anomalies of (a) precipitation (mm day ${ }^{-1}$ ) and (b) 2-m average temperature (K) for weeks 1-4. The week of the forecast is indicated in the upper right corner of the panel. The RMS error includes all the forecasts during JJAS 2011-17.

and RC3) satisfy the criteria to be an oscillatory pair and reveal spectra with peaks around 50 days. The spectra of RC2 and RC3 are broad because they are not perfectly periodic but consist of nonlinear oscillations with an average period of 50 days. Since the period of the oscillatory pair is subseasonal, it will be referred to as ISO. Further analysis of the ISO will be carried out by adding RC2 and RC3 (hereafter jointly RC23) since they are in quadrature and form two parts of the oscillation.

The magnitude of the leading eigenmodes is examined by plotting the variance of the corresponding $\mathrm{RC}$ as the percentage of the variance of the total anomaly, as shown in Figs. $3 \mathrm{~b}$ and $3 \mathrm{c}$, respectively for the $u$ and $v$ components of the RCs. The variance was calculated by using all the days of JJAS 19792017. The largest variance of up to about $12 \%$ in $u$ is present in the equatorial Pacific and Central America and its coast for both RC1 and RC23 (Fig. 3b). In RC4, significant variance is seen only over the Amazon River basin in South America. The variance of $v$ (Fig. 3c) is generally about half of that of $u$ (Fig. 3b) and has large values in RC1 over the equatorial Pacific, Central America, the northern part of South America, and near the U.S. West Coast. However, the variance of $v$ is large only over Central America in RC23 and over the eastern equatorial Pacific and Central America in RC4. The variance over CONUS is small in both $u$ and $v$. 
(a) Spectra of RCs

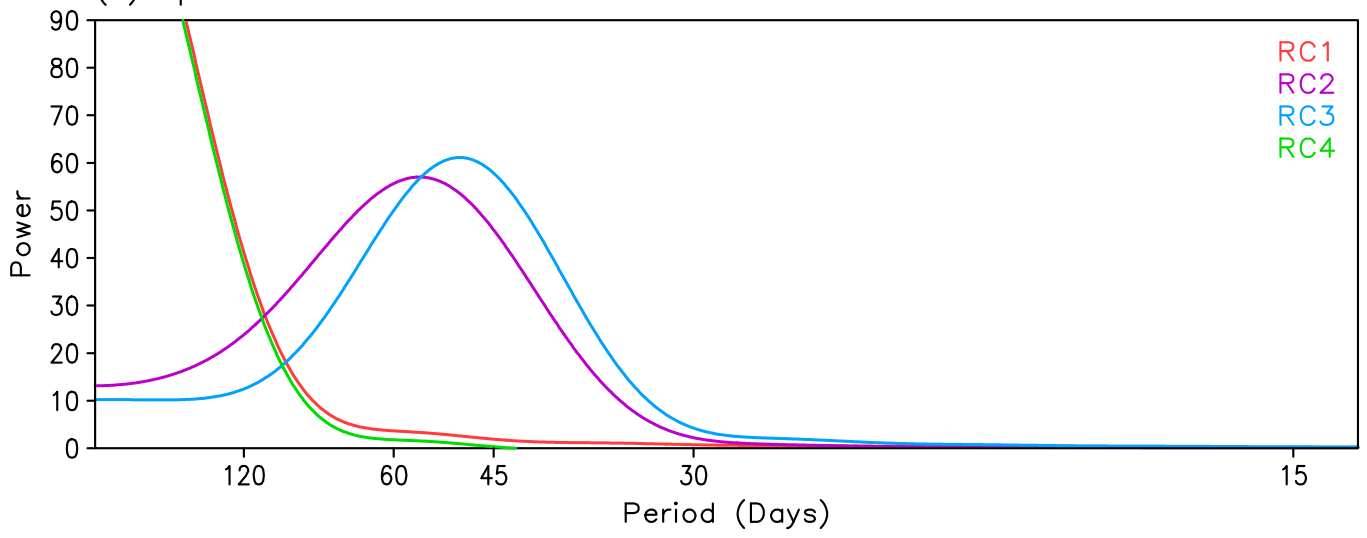

(b) Variance of $u$
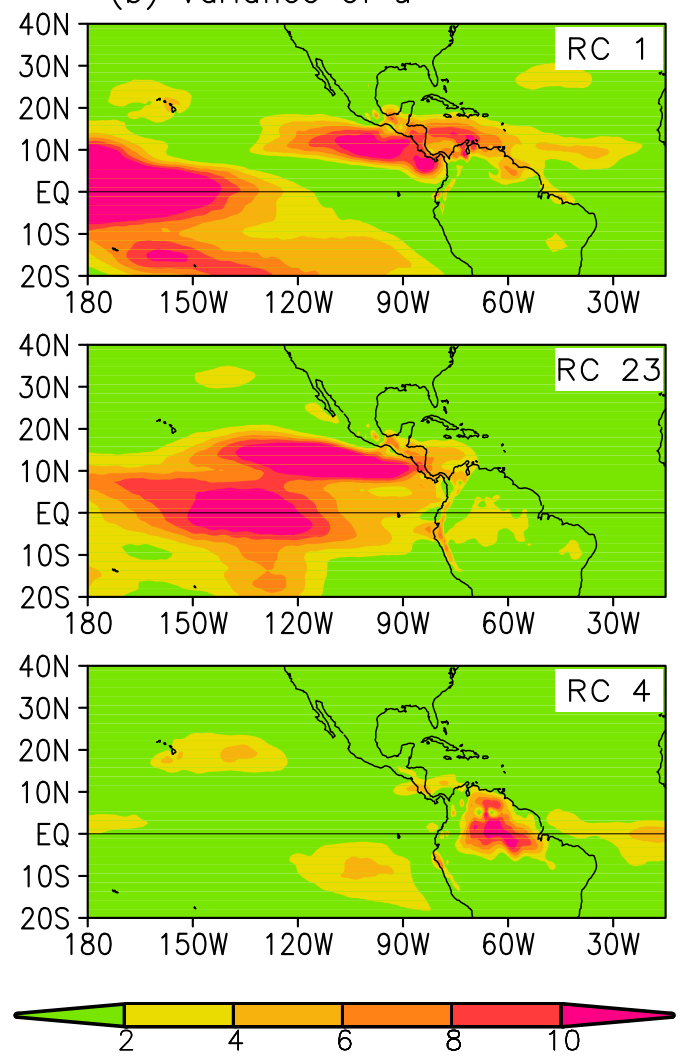

(c) Variance of $v$
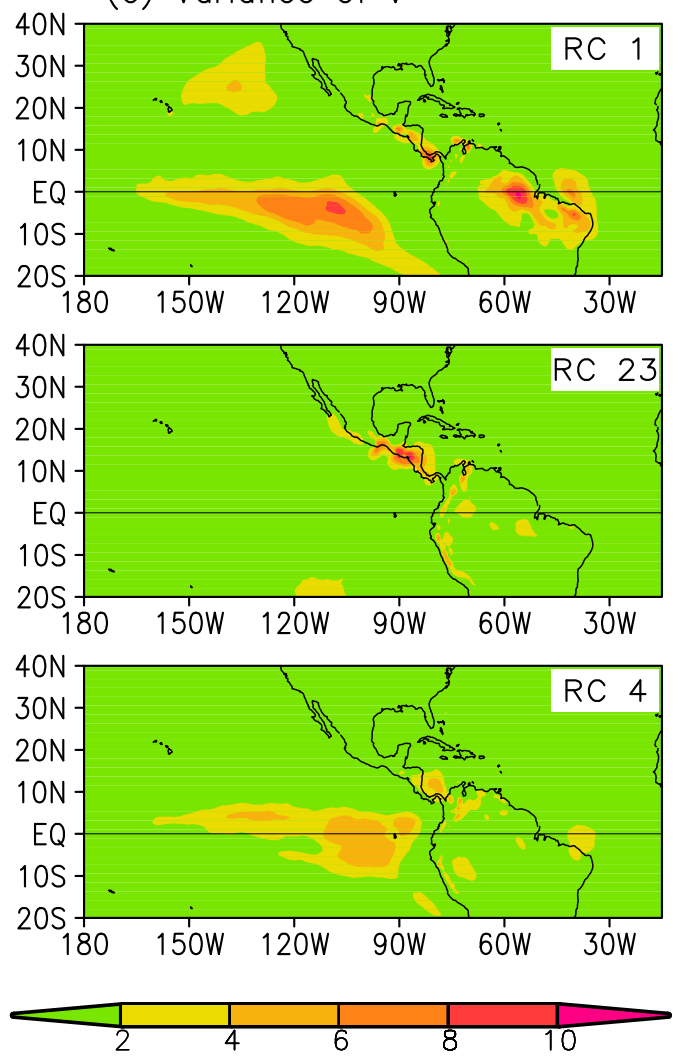

FIG. 3. (a) Power spectra of PC1 of RC1 (red), RC2 (purple), RC3 (blue), and RC4 (green) of ERA-Interim 850$\mathrm{hPa}(u, v)$ obtained from MSSA of daily anomalies of JJAS 1979-2017. Variance of RC1, RC23, and RC4 of (b) $u$ and of (c) $v$ is in percent of total variance of each variable.

The first EOF (EOF1) in each of RC1 and RC4 and the first two EOFs of RC23, which are in quadrature, explain most of the variance $(>90 \%)$ of the corresponding RC. Therefore, it is sufficient to examine EOF1 and PC1 to understand the spacetime structure of the corresponding mode. In Fig. 4, EOF1 is plotted for RC1, RC23, and RC4 as horizontal wind vectors. The strongest winds in RC1 (Fig. 4a) are mainly zonal with westerlies in the central equatorial Pacific and easterlies that extend from the North Atlantic to the eastern Pacific across
Central America. These easterlies converge with the westerlies in the northern Pacific and travel northward while the westerlies in the Pacific to the south of the equator become northwesterlies and diminish near the west coast of South America. Weak westerlies are present over the United States and a somewhat anticyclonic circulation exists over the North Atlantic. The dominant winds in RC23 (Fig. 4b) consist of intense westerlies in the tropical Pacific (around $10^{\circ} \mathrm{N}$ ) that are stronger near the coast of Central America and become weak 

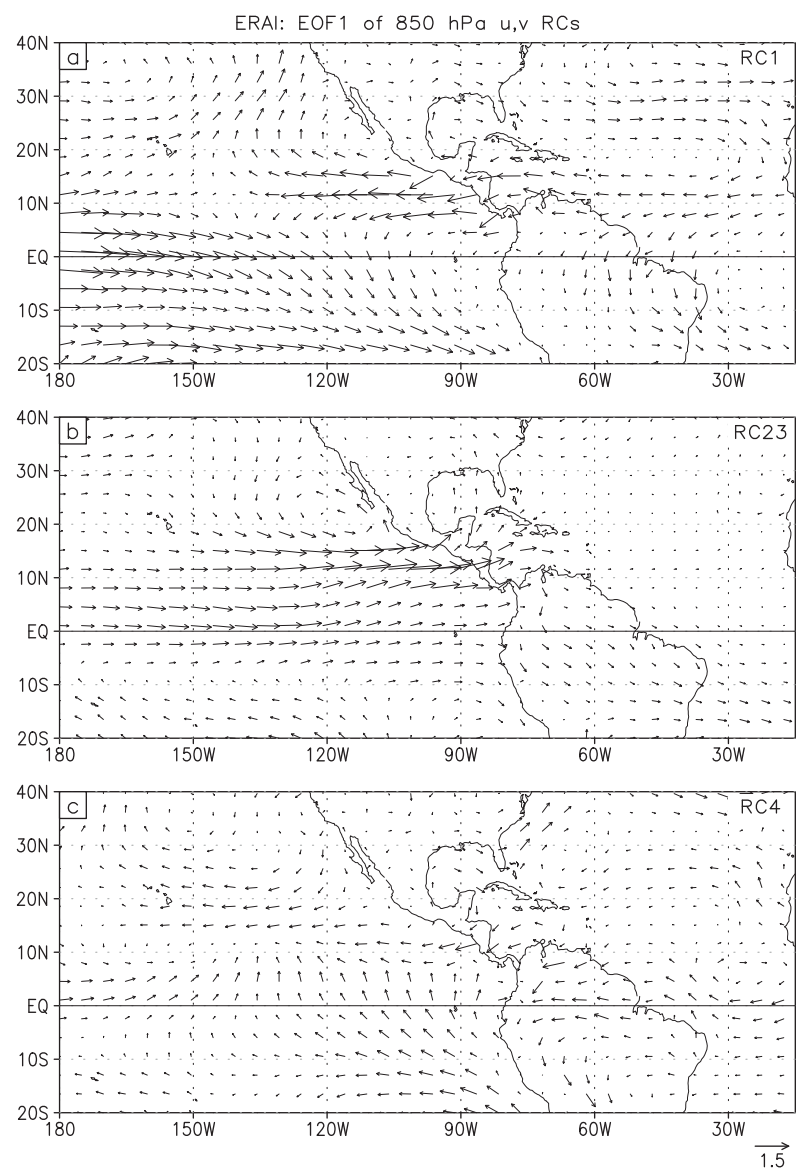

FIG. 4. EOF1 of (a) RC1, (b) RC23, and (c) RC4 of ERA-Interim $850-\mathrm{hPa}(u, v)\left(\mathrm{m} \mathrm{s}^{-1}\right)$ obtained from MSSA of daily anomalies of JJAS 1979-2017.

northerlies in the Gulf of Mexico. A moderate cyclonic circulation is present near the west coast of the United States and Mexico while the winds are very weak over the Atlantic and the United States. The winds in RC4 (Fig. 4c) are moderate with an anticyclonic circulation in the northern Pacific and southeasterlies from the eastern Pacific converging with the westerlies in the central equatorial Pacific. Weak to moderate easterlies are present over the Atlantic and the Amazon River basin.

The temporal variation of EOF1 of each $\mathrm{RC}$ is determined by the daily PC1 as shown in Fig. S1 in the online supplemental material for the period JJAS 1979-2017, where each PC is divided by its standard deviation. To show the variability within a season, PC1 is plotted in Fig. S2 for JJAS 1997 as an example. The PC of RC1 exhibits interannual variability with several strong positive (negative) years coinciding with El Niño (La Niña) events, such as 1997 and 1988 (Fig. S1a). During such years, the PC of RC1 varies with the same sign throughout the season as seen, for example, during 1997 (Fig. S2a). For this reason, $\mathrm{RC} 1$ will be referred to as seasonally persisting mode. The PC1 of the oscillatory mode RC23 (Fig. S1b) varies with positive and negative values every year with different amplitude
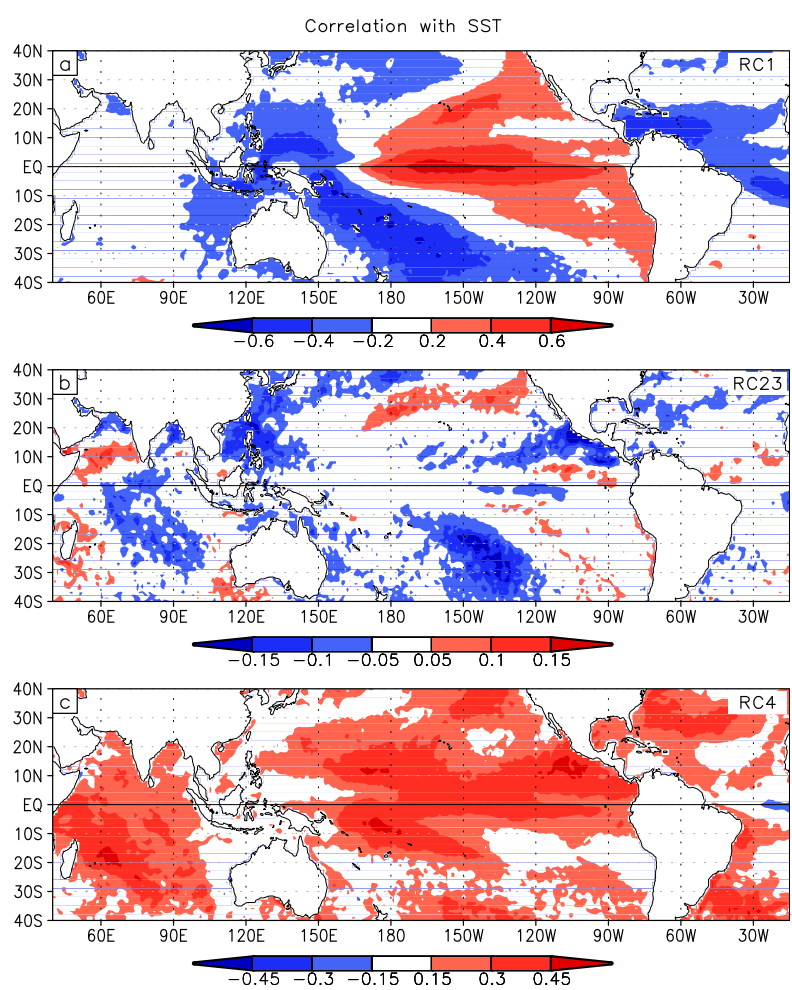

FIG. 5. Point correlation of PC1 of (a) RC1, (b) RC23, and (c) RC4 of ERA-Interim 850 -hPa $(u, v)$ with the daily anomaly of SST.

but does not show a preference toward interannual variability such as ENSO. Within a season, such as during 1997 (Fig. S2b), the oscillatory behavior is evident with the modulation of both amplitude and frequency at an average period around 50 days. From the variability of PC1 of RC4 (Fig. S1c), it is apparent that this mode consists of an increasing trend which is steeper after 2000. This trend mode is also seasonally persisting in most of the years, as shown, for example, during 1997 (Fig. S2c).

To identify the MSSA modes with known phenomena, such as ENSO, and to understand the relation with ocean variability, a correlation analysis with the SST was performed. The point correlation between the PC1 of each RC and the daily SST anomalies for the period JJAS 1982-2017 was computed using the OISST2 dataset, which is available only after 1982. The correlation with the PC1 of RC1 (Fig. 5a) shows high correlation in the equatorial Pacific with the well-known horseshoe pattern associated with ENSO, consisting of positive values to the east surrounded by negative values in the west. This correlation is consistent with the time series of PC1 of RC1 (Fig. S1a), which also shows large amplitudes for most of the ENSO years during this period. The first MSSA eigenmode, represented by $\mathrm{RC} 1$, is thus essentially a seasonally persisting ENSO mode. The correlation of the ISO (RC23) is very weak with no spatial pattern of any known phenomena (Fig. 5b) and indicates a weak role of the ocean-atmosphere interaction for the ISO. For the trend mode RC4, the correlation is moderate and positive over most of the oceanic region shown (Fig. 5c) and points toward a possible relation with the warming trend of 
the oceans. These three leading modes seem to have the potential to exhibit enhanced predictability in precipitation and temperature over the CONUS because of their variability at slower time scales with more regular behavior.

\section{b. Leading modes of horizontal wind in model forecasts}

The objective of this study is to assess the predictability of UFS and to identify the sources of potential subseasonal predictability. For this purpose, the leading modes of variability in the observed low-level horizontal circulation have already been obtained. A similar decomposition by applying MSSA on UFS forecasts is not feasible because of the length of each forecast. Although the forecasts of UFS cover the period 201117 , each individual forecast is only 35 days long. Therefore, the forecasts are not suitable for representation in lagged time coordinates with a lag window of 61 days required for MSSA as done in the case of observed winds to obtain the subseasonal modes. An alternate method is adopted to obtain the spacetime patterns of MSSA modes in UFS forecasts as follows. The EOFs and PCs of the RCs of the three leading MSSA modes in observed 850-hPa winds (i.e., RC1, RC23, and RC4) are already available. While EOF1 explains about $90 \%-96 \%$ of the variance of the RCs, the first six EOFs of each RC together capture almost all the variance $(>99.5 \%)$ of the corresponding $\mathrm{RC}$. The first six PCs of each RC in the observation are projected on the daily anomalies of the 850-hPa horizontal wind of the forecasts to obtain the six EOFs of the corresponding RC in the forecasts. For each projection, the corresponding PC was concatenated for the period of JJAS 2011-17. The six PCs and resulting six EOFs of the forecasts are suitably multiplied and added to obtain the corresponding $\mathrm{RC}$ of the forecasts. Thus, the RC1 (ENSO mode), RC23 (ISO), and RC4 (trend) in model forecasts are obtained for each of the 56 forecasts during JJAS 2011-17. The method of projecting observed EOFs or PCs on the total anomalies of model forecasts has been widely used to provide forecasts and assess the predictability of the corresponding mode, such as in MJO forecasts (e.g., Wheeler and Hendon 2004; Gottschalck et al. 2010). Further, the first six PCs of the RCs of the horizontal wind in observation are projected on the daily anomalies of precipitation and 2-m temperature in both observations and UFS forecasts to obtain the RCs of the corresponding fields. The MSSA method captures the temporal variability with a particular spatial pattern on a daily time scale. These patterns are unique and continuous. Therefore, the shorter period of 2011-17 is a subset of the unique trajectories of the longer period of time of 1979-2017. A long period of time mostly increases the confidence levels at which these modes are captured.

The EOF1s of RC1 (ENSO mode), RC23 (ISO), and RC4 (trend) of $850 \mathrm{hPa}(u, v)$ anomalies in the UFS forecasts during JJAS 2011-17, obtained by the projection method, are plotted in Fig. 6. The spatial structure and the amplitude of the winds of the ENSO mode and ISO in the model forecasts (Fig. 6) are generally similar to those of the observation (Fig. 4). The model's wind in the ENSO mode (RC1) is slightly stronger along the equator and to the north in the Pacific, near the west coast of Central America and Mexico and over the North Atlantic (Fig. 6a). The directions of the winds in the model and
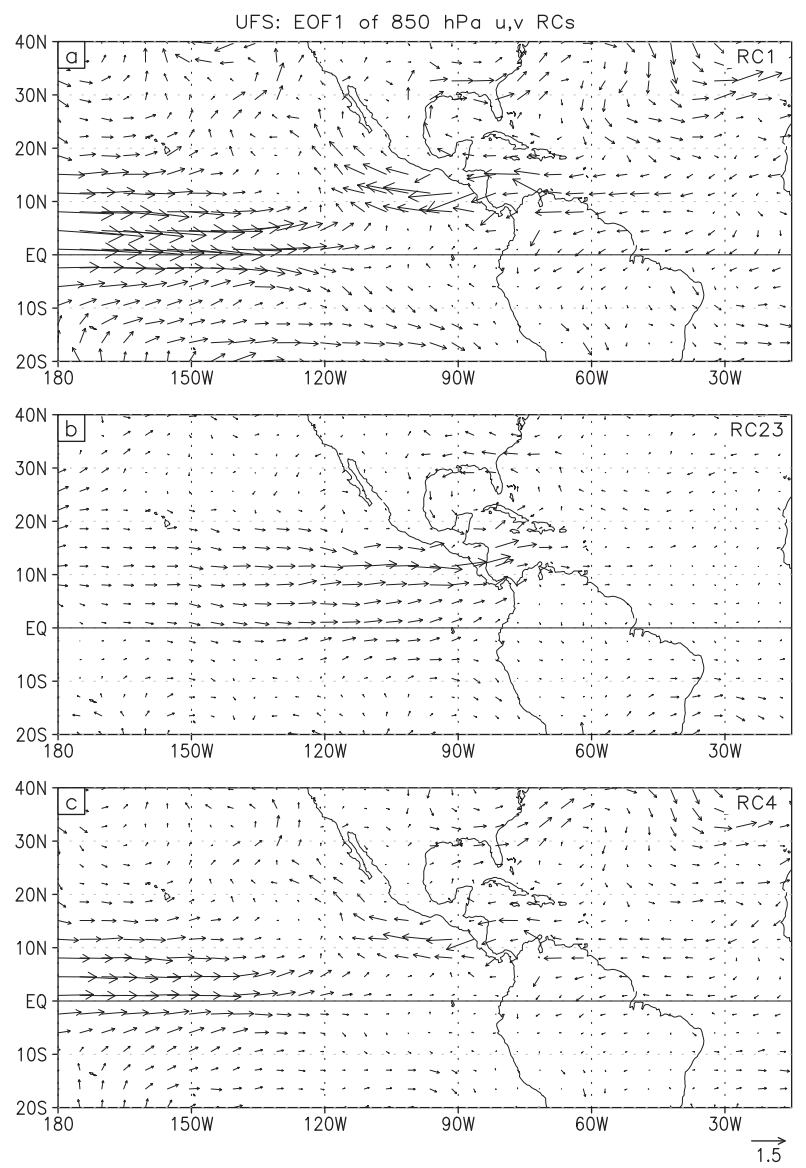

FIG. 6. EOF1 of (a) RC1, (b) RC23, and (c) RC4 of 850-hPa $(u, v)$ $\left(\mathrm{m} \mathrm{s}^{-1}\right)$ in UFS forecasts obtained by projecting the PC1 of the corresponding RC of ERA-Interim $850-\mathrm{hPa}(u, v)$. All the UFS forecasts initiated on the first of each month during JJAS 2011-17 are included.

observations are similar in most of the domain. The model has reproduced the winds of the ISO (RC23) quite well (Fig. 6b) when compared to the observation (Fig. 4b) except for slightly weaker wind near the west coast of Central America and over South America while slightly stronger over the eastern part of United States. The trend mode (RC4) in the model forecasts (Fig. 6c), however, shows some differences from the observed mode (Fig. 4c), although the general direction of the flow is similar in most of the Pacific. The model winds are weaker in the southeastern Pacific and stronger in the central Pacific. More detailed quantitative assessment of the model's performance will be presented later.

\section{c. Leading modes in precipitation and 2-m temperature}

The space-time structures of the three leading modes of variability in precipitation and 2-m temperature are now examined for both model forecasts and observations. The method of projecting the PCs of the RCs of the observed horizontal wind described earlier was used to obtain the corresponding RCs of observed and model fields. The projection method was applied on the daily anomalies of precipitation for the period JJAS 


\section{EOF1 of Precipitation Projections}

(a) GPCP
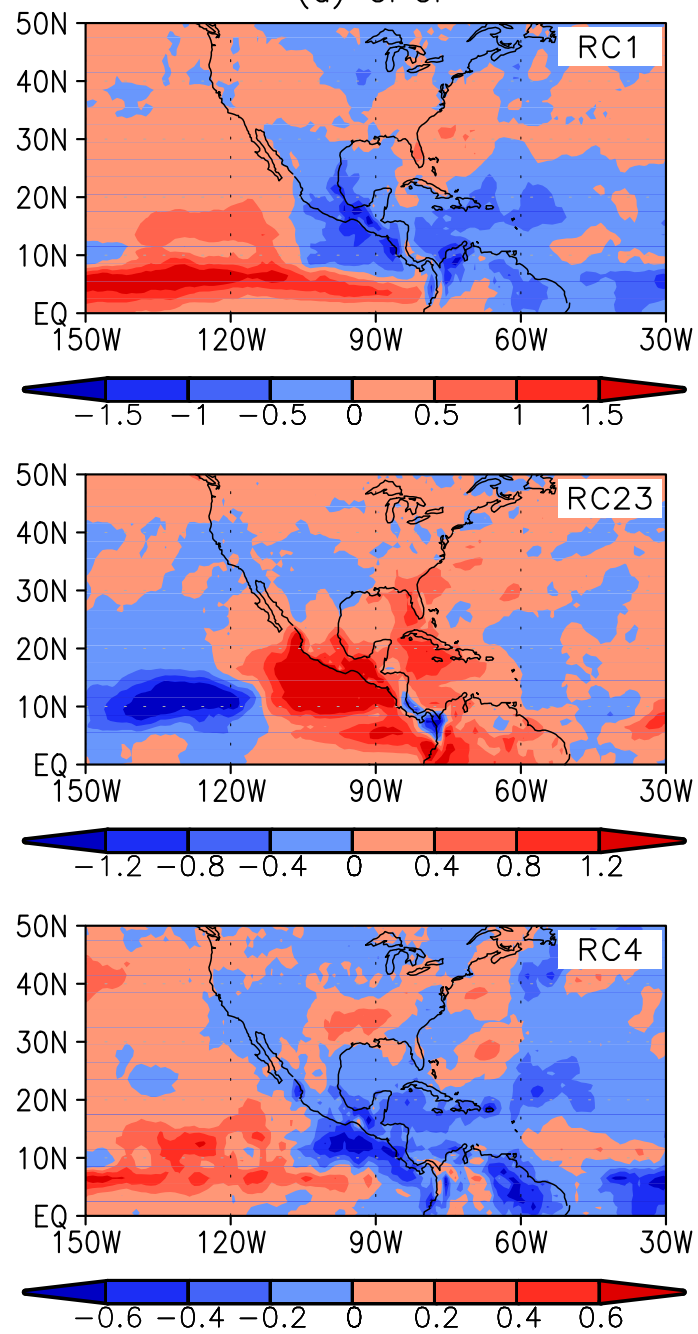

(b) UFS
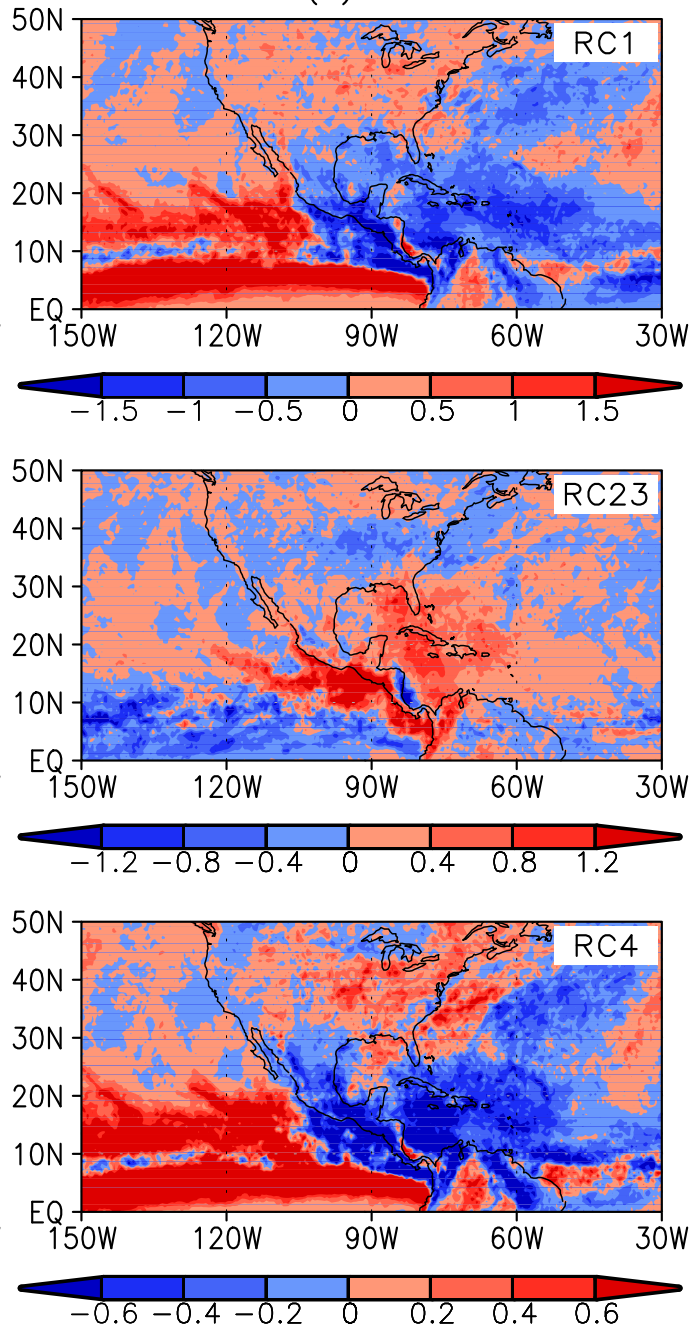

FIG. 7. EOF1 of (top) RC1, (middle) RC23, and (bottom) RC4 obtained by projecting the PC1 of the corresponding RC of ERA-Interim 850-hPa $(u, v)$ on (a) GPCP precipitation and (b) UFS forecast precipitation $\left(\mathrm{mm} \mathrm{day}^{-1}\right)$. All the UFS forecasts initiated on the first of each month during JJAS 2011-17 are included.

2011-17 in observations and model forecasts. In the observation, the leading modes were extracted separately for GPCP and CPCU precipitation. The GPCP dataset has coverage over both land and ocean regions whereas the CPCU dataset, which is only over land, has higher resolution. The EOF1s of ENSO mode (RC1), ISO (RC23), and trend (RC4) for precipitation in GPCP and UFS forecasts are shown in Fig. 7. The corresponding EOFs in CPCU and UFS precipitation are plotted in Fig. S3 where the UFS precipitation is masked over the ocean for easy comparison with CPCU. The spatial structures of precipitation in GPCP (Fig. 7a), CPCU (Fig. S3a), and UFS (Fig. 7b; see also Fig. S3b) are mostly similar in both location and magnitude but have some differences. In the ENSO mode ( $\mathrm{RC} 1$ ), the model has slightly stronger positive anomalies in the equatorial Pacific (Fig. 7b) compared to GPCP (Fig. 7a), consistent with the stronger westerlies in that location (Fig. 6a). The model reproduces the negative anomalies over Mexico, Central America, and part of the North Atlantic but the differences in the northern United States and North Atlantic correspond to weak anomalies. The anomalies over the United States in the UFS (Fig. S3b) are similar to those in the CPCU (Fig. S3a) but differ over Mexico and northeast South America. The ISO (RC23) in GPCP (Fig. 7a) has strong positive anomalies in the eastern Pacific, Central America, and the Gulf of Mexico, consistent with the strong westerlies in those regions (Fig. 4b). The ISO in the UFS forecasts (Fig. 7b) also shows strong positive anomalies in the same regions but smaller in the eastern Pacific due to relatively moderate winds (Fig. 6b). The negative anomalies present in the central Pacific are stronger in GPCP but moderate in the UFS while weaker negative anomalies are present over the United 


\section{EOF 1 of Daily Average $2 \mathrm{~m}$ Temperature Projections}

(a) CPC
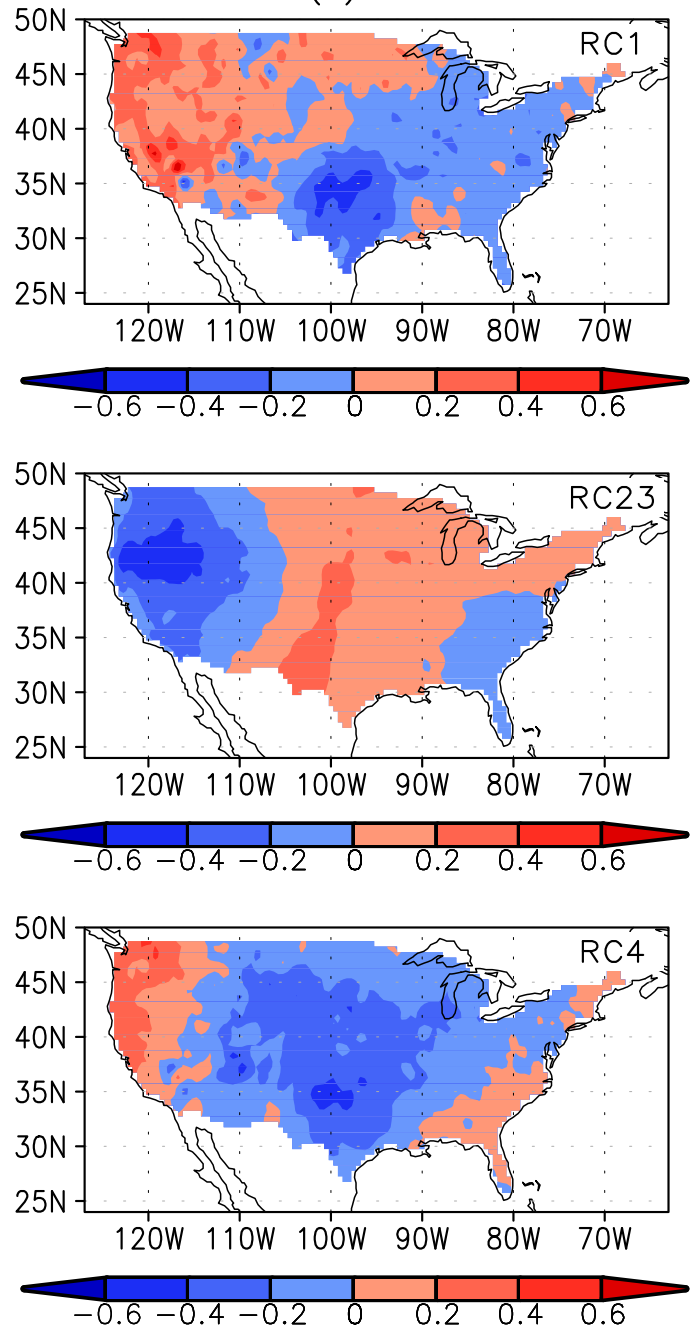

(b) UFS
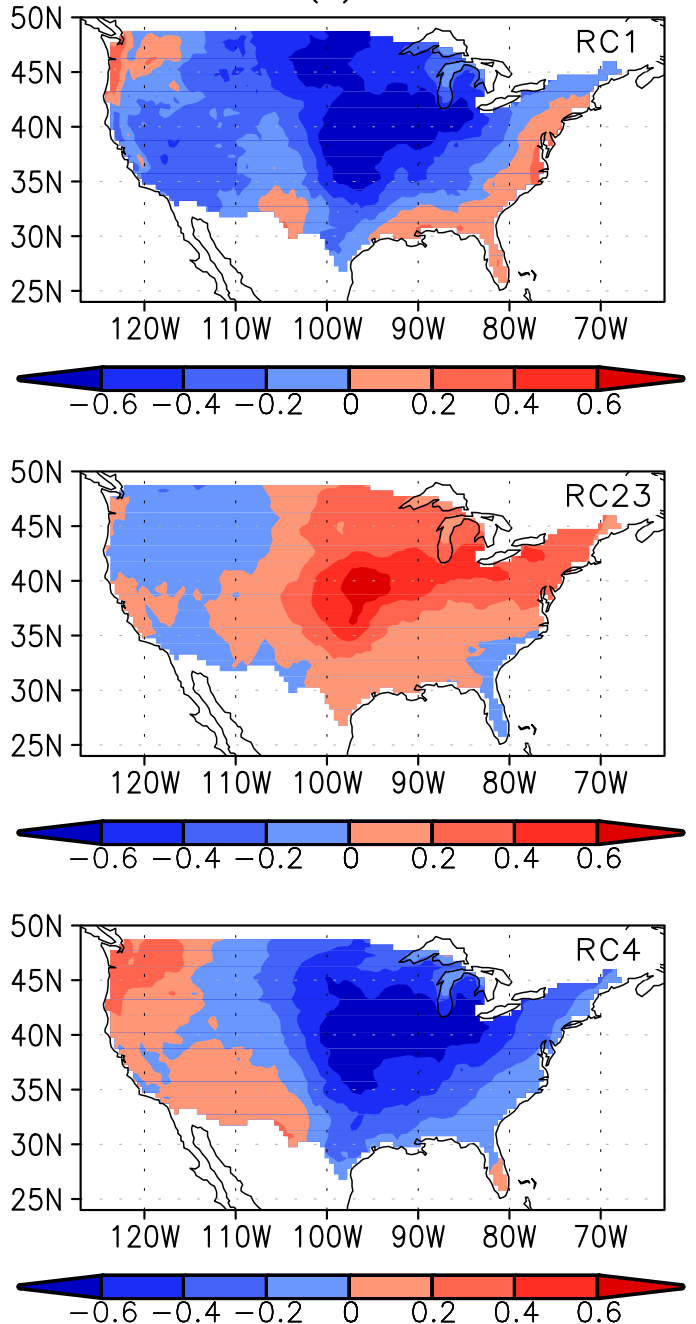

FIG. 8. EOF1 of (top) RC1, (middle) RC23, and (bottom) RC4 obtained by projecting the PC1 of the corresponding RC of ERA-Interim 850-hPa $(u, v)$ on 2-m average temperature (K) of (a) CPC observation and (b) UFS forecasts. All the UFS forecasts initiated on the first of each month during JJAS 2011-17 are included.

States in both GPCP and UFS but at different locations. The negative anomalies over the United States and Mexico are broader and in a tilted pattern in CPCU ISO (Fig. S3a), which is partially predicted by the UFS (Fig. S3b). The trend (RC4) in GPCP (Fig. 7a) consists of mostly positive anomalies over the Pacific and largely negative anomalies to the east of the Pacific. The UFS has strong positive anomalies over a large region of the equatorial Pacific (Fig. 7b), reflecting the presence of strong westerlies (Fig. 6c), while capturing the negative anomalies to the east although with slightly higher magnitude. There is more agreement between CPCU and UFS over the United States with largely positive anomalies (Fig. S3), which GPCP does not show, and with negative anomalies over the Central America.

The EOF1s of the three leading modes in 2-m daily average temperature obtained by the projection method for the period
JJAS 2011-17 are shown in Fig. 8 for CPC observation and UFS forecasts. Due to the coverage of the CPC data, this analysis is restricted to the CONUS. The ENSO mode (RC1) in the observation has a dipole-like structure with positive anomalies in the western half of the CONUS where the maximum value in several location reaches $0.5 \mathrm{~K}$. The eastern half of the CONUS consists of negative anomalies with the largest values over Texas and neighboring states. However, the ENSO mode in the UFS forecasts (Fig. 8b) consists of large values over most of the CONUS. The positive anomalies are confined to northwest and the eastern and southern coastal states. The ISO (RC23) of temperature has negative anomalies over the western and southeastern states and positive anomalies over the rest of the CONUS in CPC observation (Fig. 8a). This pattern is largely reproduced by the UFS (Fig. 8b) but with 
different magnitudes. The negative anomalies in the model are weaker and also cover slightly lesser area while the positive anomalies are stronger with maximum values over the Midwest. In the CPC observation, the trend (RC4) consists of negative anomalies over most of the CONUS with higher values in the Midwest and southern states and positive anomalies in part of the western, northeastern and southeastern states. The UFS largely captures the observed pattern but the negative anomalies extend to the east coast except for a part of Florida. The positive anomalies cover a slightly larger area in the western part. A similar analysis of the daily maximum 2-m temperature (Fig. S4) shows almost the same patterns as in the daily average temperature (Fig. 8) in all the three modes.

\section{d. Space-time evolution of ISO}

The ENSO mode and the trend are seasonally persisting while the ISO varies within a season with an average period of 50 days. The space-time structure of the ISO within a season is of interest to understand its propagation and to assess the model's ability to predict such evolution. The space-time structure of the ISO is best understood with the help of phase composites. Following the method described by Moron et al. (1998), the amplitude $A(t)$ and phase $\theta(t)$ of the ISO, as a function of time $t$, are determined. Since $\theta$ varies from 0 to $2 \pi$ during each cycle of the ISO, eight phase intervals, each of length $\pi / 4$, are considered. The phase composites of the ISO $\mathrm{RCs}$ are constructed by averaging the corresponding $\mathrm{RC}$ in the phase intervals $(k-1) \pi / 4 \leq \theta \leq k \pi / 4$, with $k=1,2, \ldots, 8$, over the period of analysis. For brevity, the phase interval $k$ will be referred to as phase $k$.

The composites of $850-\mathrm{hPa}(u, v)$ of ISO (RC23) in observation (ERAI) and UFS forecasts for the period JJAS 2011-17 are plotted as vectors for the first half of the oscillatory cycle (i.e., phases 1-4) in Fig. 9. The composites of the second half of the cycle (i.e., phases 5-8) are almost identical to the first half but with opposite sign because of the coherent and oscillatory nature of the ISO, and therefore not shown. In phase 1, strong westerlies are present in the equatorial Pacific, both to the north and south of the equator, in both ERAI (Fig. 9a) and UFS (Fig. 9b). The westerlies in ERAI extend up to the coast of Central America but the UFS shows easterlies near the coast. Similarly, the westerlies in the North Pacific reach the west coast of the United States in ERAI while the westerlies in UFS do not. The westerlies in ERAI propagate eastward crossing Central America and reaching the Gulf of Mexico during phases 2 and 3 . The UFS also shows eastward propagation of westerlies but with weaker amplitude over Central America. In phase 3, easterlies appear in the southern part of the Pacific in ERAI and grow in amplitude in phase 4 . Weak easterlies begin to appear during phase 4 in the UFS forecasts. Both the ERAI and UFS composites show weaker anomalies over the CONUS in all the phases.

Similar phase composites were constructed for the ISO RC in precipitation of observation (both GPCP and CPCU) and UFS forecasts for the period JJAS 2011-17, as shown in Fig. 10 and Fig. S4. The strong positive anomalies of precipitation (up to about $2 \mathrm{~mm} \mathrm{day}^{-1}$ ) that appear in the eastern Pacific during phase 1 in GPCP (Fig. 10a) move eastward across Central
America and reach Florida and Cuba in phases 2 and 3 and diminish in phase 4 . The propagation of precipitation is consistent with the movement of westerlies (Fig. 9a) in transporting the moisture to the appropriate regions. The UFS also shows eastward moving positive anomalies in the same region but with lower magnitude. The GPCP composites also reveal negative anomalies developing in the equatorial Pacific in phase 3 and strengthening and moving slowly eastward in phases 3 and 4 . The negative anomalies that appear in phase 2-4 over the equatorial Pacific in the UFS are weaker and cover a smaller region but are also accompanied by positive anomalies. The composites over the CONUS and the other land regions are better understood by comparing the higher-resolution CPCU precipitation and UFS forecasts in Fig. S5 (note the different scale). The negative anomalies in CPCU over Mexico and the southern United States in phase 1 strengthen, expand, and move northeastward in phases $2-4$ (Fig. S5a). The UFS forecasts also show similar movement of negative anomalies but with lesser magnitude during phases 1-3 (Fig. S5b). The positive anomalies over the U.S. Midwest, Florida, and Central America and their strengthening and movement in CPCU are also reproduced by the UFS forecasts covering a slightly larger region over the United States. There are discrepancies between CPCU and UFS in the patterns over South America.

During the boreal summer, the leading mode of variability in the Indian monsoon is an ISO that has strong northward and eastward propagation extending over the Pacific (Krishnamurthy and Shukla 2008; Krishnamurthy and Achuthavarier 2012; Hazra and Krishnamurthy 2015). There seems to be a phase relation between monsoon ISO and the ISO (RC23) of this study. To examine this possibility, the ISO phase composites of GPCP and UFS precipitation are plotted over an extended region in Fig. S6. The GPCP composites show a large tilted band of negative anomalies over the Indian peninsula and extending from the Arabian Sea to the central Pacific in phase 1 and moving northeastward in phases 2 and 3 (Fig. S6a). At the same time, positive anomalies are present near the west coast of Mexico and Central America (which was already discussed). The tail of the negative anomalies from the Indian monsoon reaches the edge of the eastern Pacific in phase 4 while positive anomalies from the Indian Ocean have reached the Indian peninsula to start the second half of the ISO. The UFS forecasts are able to reproduce the extended band of negative anomalies over India and the Pacific and its movement although with lesser magnitude. The UFS also captures the outof-phase relation between the eastern Pacific and the Indian monsoon region.

The ISO phase composites of the 2-m mean temperature of CPC observation and UFS forecasts, shown in Fig. S7, are now examined. The CPC temperature consists of negative anomalies over most of the CONUS with the largest values (up to about $0.6 \mathrm{~K}$ ) over the Midwest and positive anomalies along the west coast and along a part of the southern states in phases 1 and 2 (Fig. S7a). The UFS forecasts also capture these patterns in phases 1 and 2 although with different locations of the large values and a patch of positive anomalies in the Northeast (Fig. S7b). In phases 3 and 4, the negative anomalies shrink to the western region while positive anomalies expand over the 
Phase composites of RC23 winds

(a) ERAl
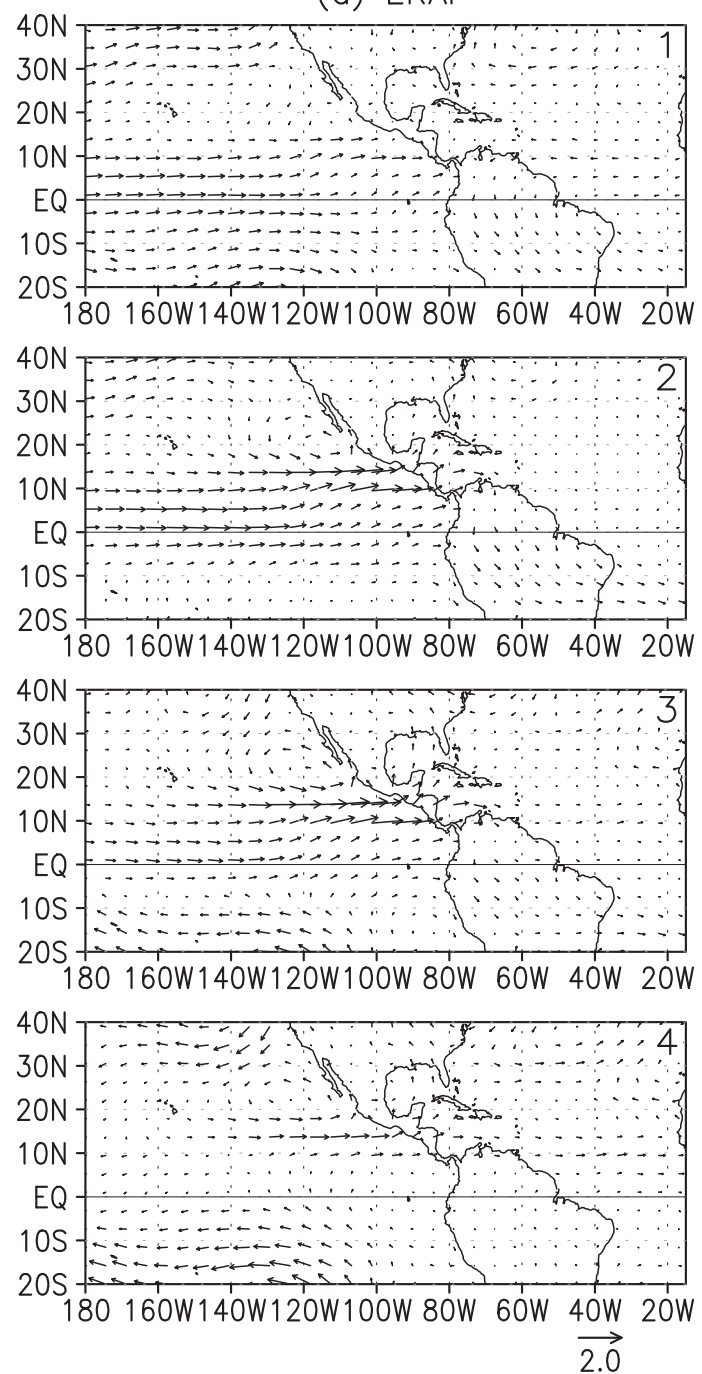

(b) UFS

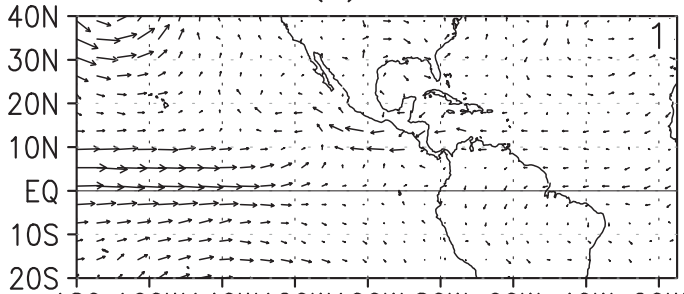

180 160W140W120W100W 80W 60W 40W 20W
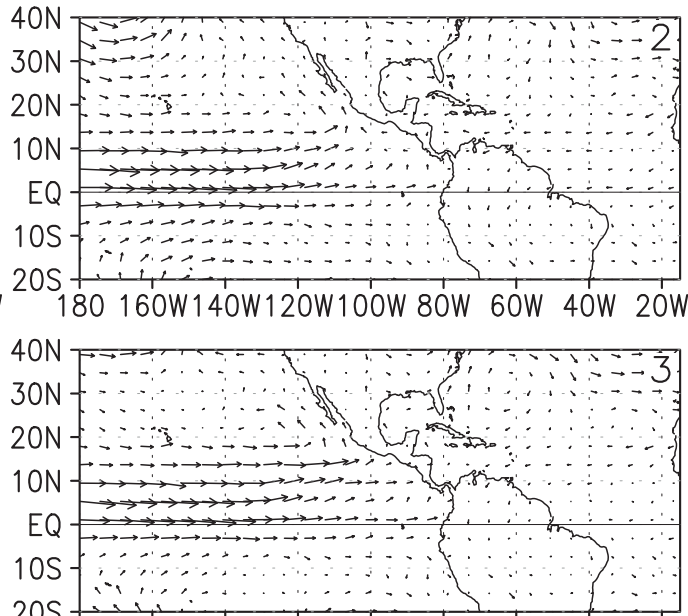

180 160W140W120W100W 80W 60W 40W 20W

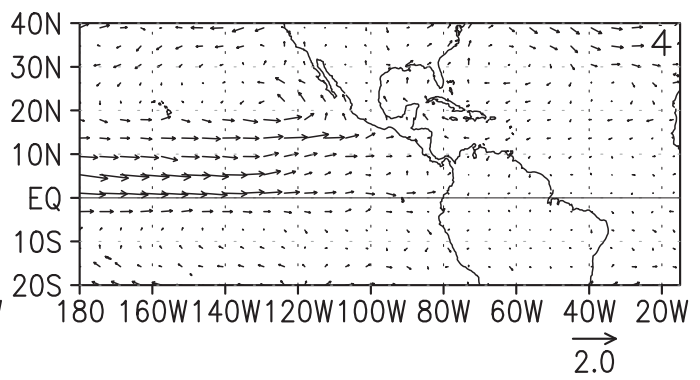

FIG. 9. Phase composites of RC23 $\left(\mathrm{m} \mathrm{s}^{-1}\right)$ of $850-\mathrm{hPa}(u, v)$ in (a) ERA-Interim and (b) UFS forecasts shown for four phases (1-4) of half a cycle of the oscillation. The phase interval is indicated in the upper right corner of the panel. The UFS composites include all the forecasts during JJAS 2011-17.

eastern half. However, in the UFS forecasts, the negative anomalies with higher values still cover a large area in the Midwest and neighboring region while positive anomalies expand in the east and west. There is no discernable propagation associated with the changes in temperature during the course of the ISO cycle.

\section{Predictability of the leading modes}

Earlier in section 3, the errors of the weekly anomalies in the UFS forecasts were examined for the total anomalies. In this section, further quantitative assessment of the predictability of the UFS will be carried out for week 1-4 forecasts over the CONUS. Specifically, the predictability in the ENSO mode, ISO, and trend mode will be studied to explore if any of these modes correspond to sources of predictability at subseasonal time scale. For this purpose, the RMS errors in weekly anomalies of RC1, RC23, and RC4 in the week 1-4 forecasts will be assessed. The spatial correlation of the weekly anomalies of each mode will also be examined.

\section{a. Forecast errors}

The RMS errors in the UFS forecasts of weekly average $\mathrm{RC} 1, \mathrm{RC} 23$, and $\mathrm{RC} 4$ for $850-\mathrm{hPa}(u, v)$, precipitation and 2-m temperature were computed exactly the same way as in the case of total anomalies (section 3). The RMS error for week 1-4 for each variable and each mode was computed by averaging the difference between the forecast and observation over all the 56 forecasts at each grid point over CONUS during JJAS of 2011-17. The RMS errors of $850 \mathrm{hPa}(u, v)$ in the ENSO mode 
Composites based on phases of RC23

(a) GPCP precipitation
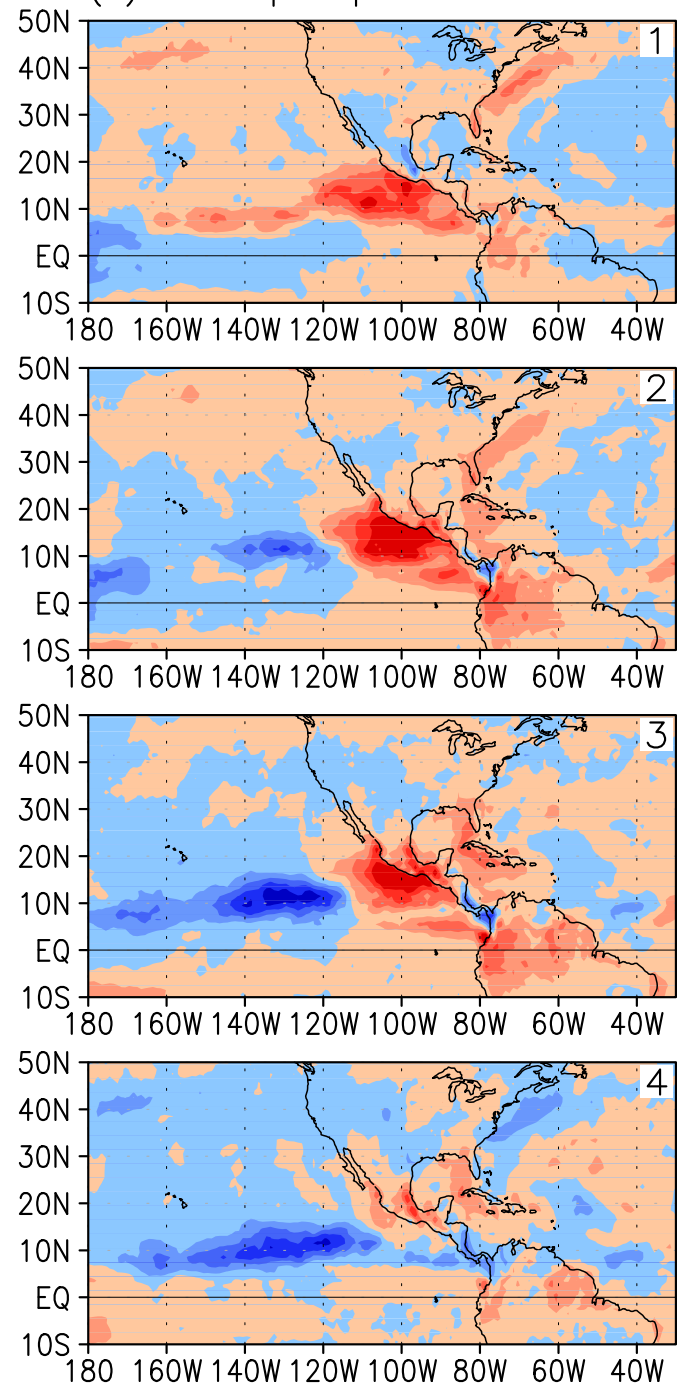

(b) UFS precipitation

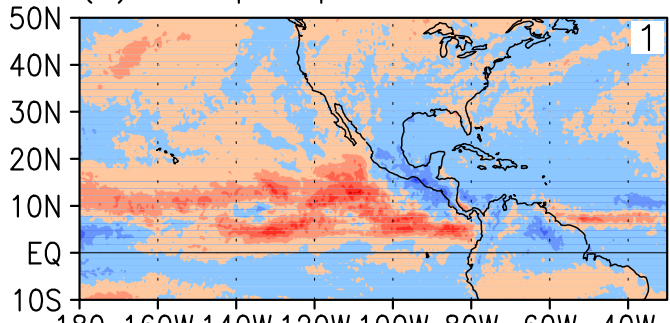

180 160W 140W 120W 100W 80W 60W 40W
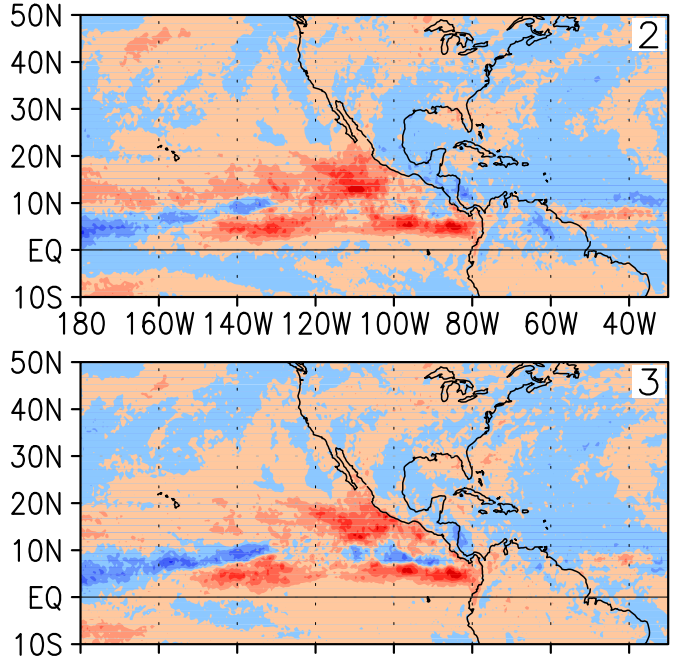

180 160W 140W 120W 100W 80W 60W 40W

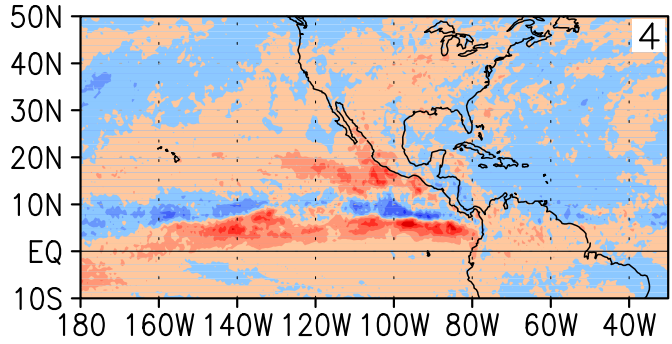

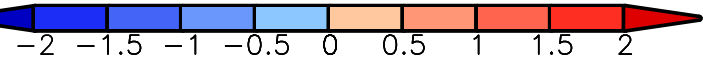

FIG. 10. Phase composites of projected RC23 of (a) GPCP precipitation and (b) UFS precipitation (mm day ${ }^{-1}$ ) for four phases (1-4) of half a cycle of the oscillation. The phase interval is indicated in the upper right corner of the panel. The UFS composites include all the forecasts during JJAS 2011-17.

(RC1) are shown in Fig. 11. The errors in the zonal wind (Fig. 11a) in week 1 are smaller in the western half of the CONUS and in the southern states and larger in the Midwest and Northeast. The errors grow only by a small amount during weeks 2 and 3 and even reduce over the Midwest in week 4. The errors in the meridional wind (Fig. 11b) are low over much of the CONUS but higher over parts of the Midwest, Texas, and neighboring states in week 1 . The errors grow only in the Midwest and the region south of it in week 2. During weeks 3 and 4 , there is almost no further growth over the CONUS. Thus, in the western half of the CONUS, the error growth in ENSO mode of the 850 -hPa horizontal wind is minimal. The errors of the ENSO mode in the precipitation and 2-m average temperature are shown in Figs. 12a and 12b, respectively. The errors in the precipitation (Fig. 12a) are small over the western states in all the four weeks while they are larger in the eastern half with many areas of maximum values. There is almost no growth of errors in precipitation during the four weeks over the CONUS. The standard deviation of the observed RC1 (figure not shown) is about 2-3 times the errors in Fig. 12a, thereby ruling out that the errors have already reached saturation (i.e., $\sqrt{2}$ times standard deviation). For the 2-m average temperature, the errors during week 1 are uniformly small except for slightly higher value in the central part (Fig. 12b). The errors grow in weeks 2 
RMS error in RC1

(a) $850 \mathrm{hPa} \mathrm{u}$
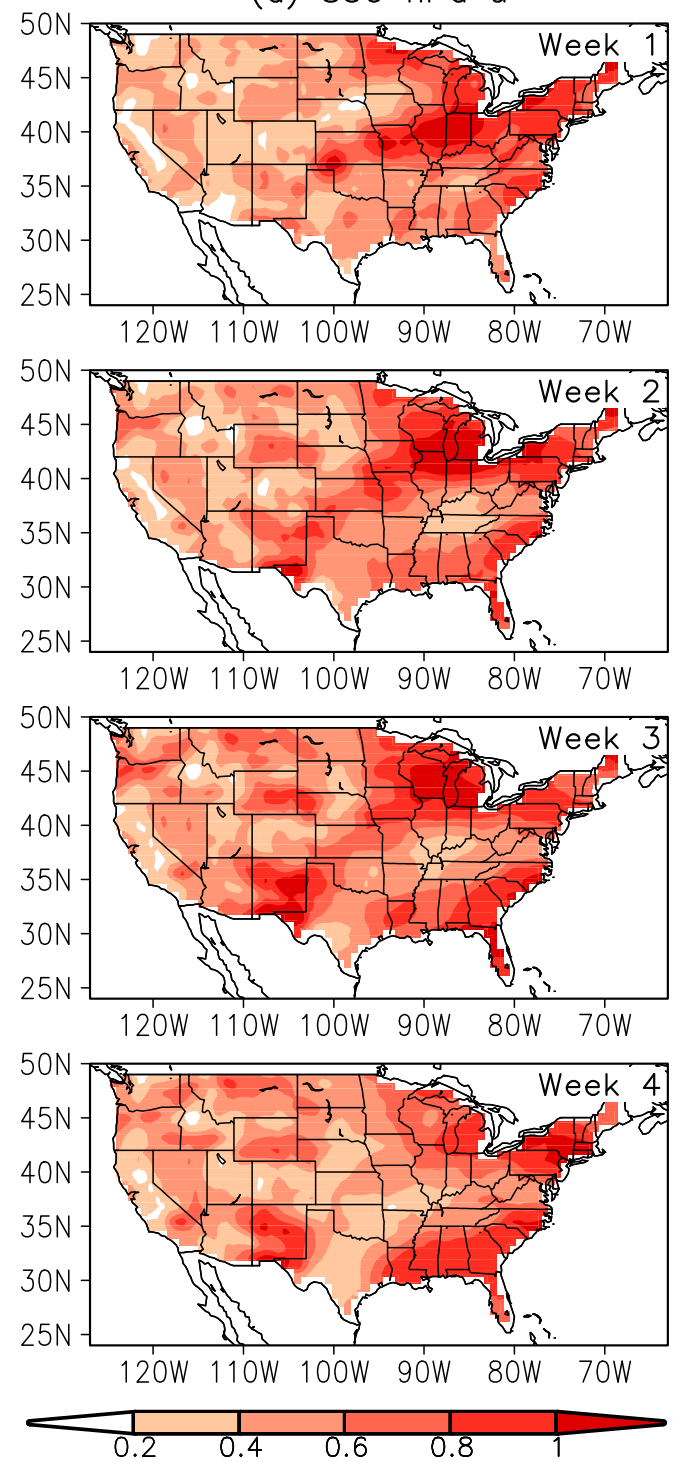

(b) $850 \mathrm{hPa} \mathrm{v}$
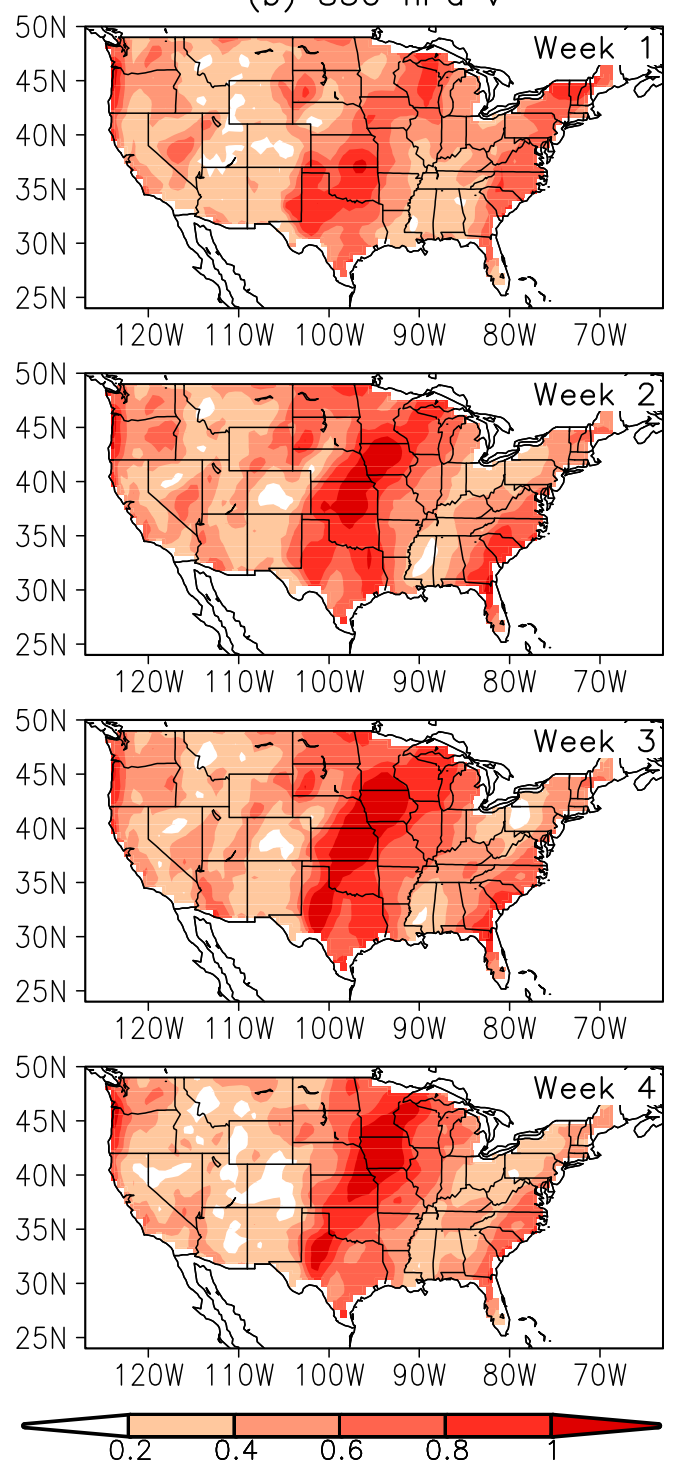

FIG. 11. RMS error of UFS forecasts in the weekly average RC1 of (a) 850-hPa zonal wind $u$ ( $\mathrm{m} \mathrm{s}^{-1}$ ) and (b) 850hPa meridional wind $v\left(\mathrm{~m} \mathrm{~s}^{-1}\right)$ for weeks $1-4$. The week of the forecast is indicated in the upper right corner of the panel. The RMS error includes all the forecasts during JJAS 2011-17.

and 3 with larger values over much of the northern and western regions and do not grow further in week 4 . The errors in the horizontal wind and the precipitation indicate that the model's performance in the western half of CONUS is better in the ENSO mode, which may be a reflection of the seasonally persistent nature of the mode and role of the ocean-atmosphere interaction.

The errors in the weekly average 850 -hPa horizontal wind of the ISO (RC23) are shown in Fig. 13. The errors in the zonal wind (Fig. 13a) are quite small over the western states, moderate over the Midwest, and large in the eastern part during week 1 . The errors remain more or less constant over most of the CONUS and grow only in the eastern region. In the meridional wind (Fig. 13b), the errors are small over the CONUS except for larger values over part of the Midwest in week 1 . The errors in the Midwest grow during week 2 but diminish during weeks 3-4 and the errors do not grow further over the rest of the CONUS. The errors in the precipitation of the ISO (RC23), shown in Fig. 14a, are smaller over western half of the CONUS and parts of the eastern half in week 1 . This pattern of errors and their magnitude remain almost the same during weeks 2-4. The errors in 2-m average temperature also show a similar pattern of almost no growth during the four weeks (Fig. 14b). The errors are uniformly small over CONUS except for a small 
RMS error in RC1

(a) Precipitation
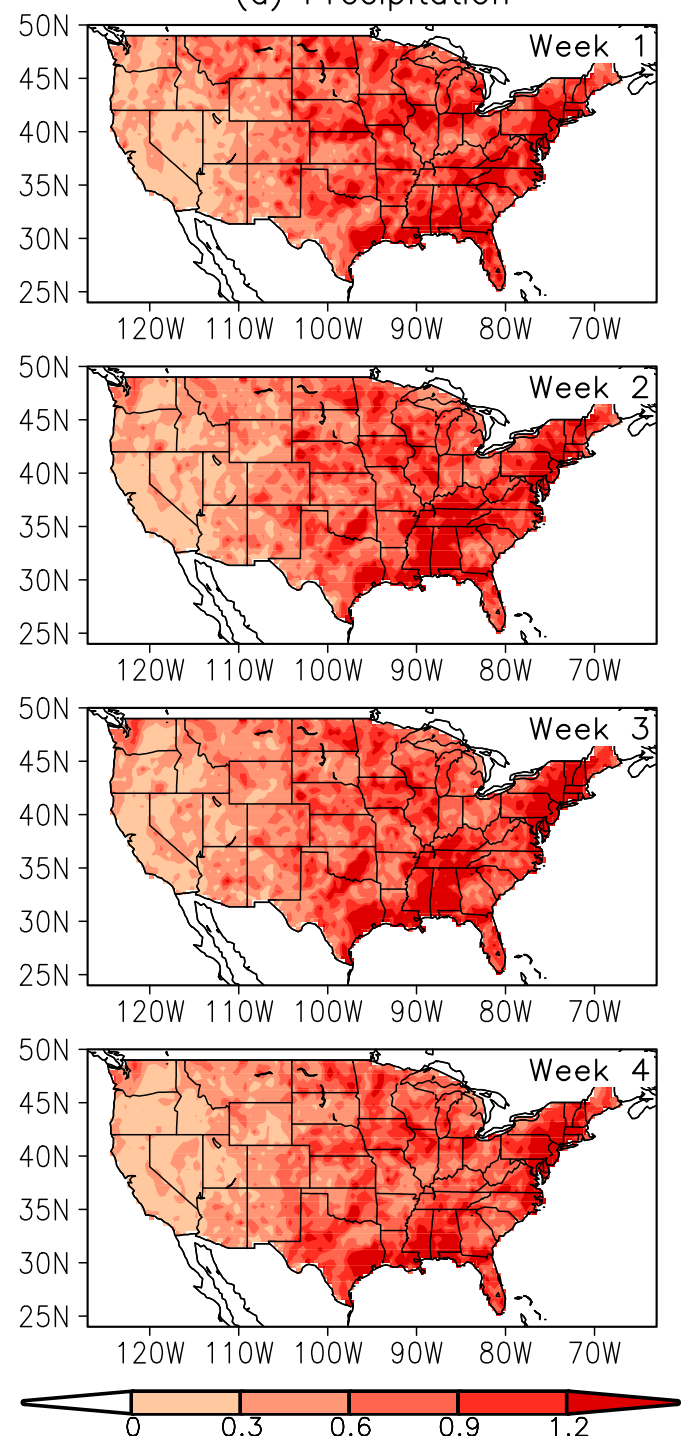

(b) $2 \mathrm{~m}$ Temperature
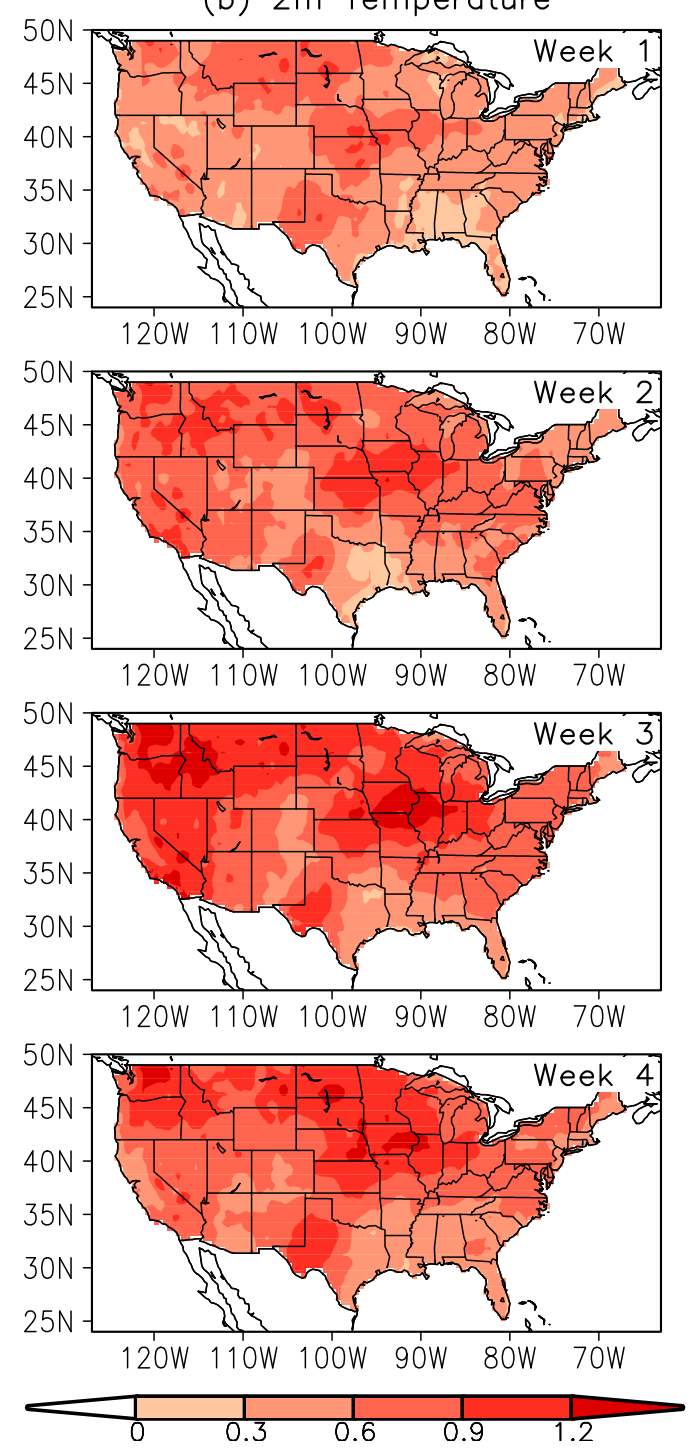

FIG. 12. RMS error of UFS forecasts in the weekly average RC1 of (a) precipitation ( $\mathrm{mm} \mathrm{day}^{-1}$ ) and (b) 2-m average temperature $(\mathrm{K})$ for weeks $1-4$. The week of the forecast is indicated in the upper right corner of the panel. The RMS error includes all the forecasts during JJAS 2011-17.

region in the Midwest in week 1 and further reduce by week 4. The near-absence of error growth in all the field indicates better predictability of the ISO mode possibly because of the almost regular and oscillatory behavior of the mode. While the ENSO mode shows better predictability over the western half of the CONUS, the ISO is better predicted over the entire region.

The error growth of the trend (RC4) in the 850 -hPa horizontal wind is shown in Fig. 15. In week 1, larger errors are present in the southern part in the zonal wind (Fig. 15a). The errors grow further in the eastern part during weeks 2-3 and over almost the entire eastern half during week 4 . The meridional wind has uniformly small errors over the CONUS except over Texas and neighboring states in week 1 (Fig. 15b). By week 4, the errors are moderately large over the central part of the CONUS. The errors in precipitation of the trend mode (Fig. 16a) in week 1 are small in the western states and large over the eastern half with maximum over several scattered locations. The errors do not grow much over most of the CONUS during weeks $2-4$. In the 2-m average temperature, the errors in the trend mode are small during week 1 over the CONUS except for a part of the Midwest. The errors grow by a small amount during weeks $2-4$. The structure and growth of errors in the horizontal wind and the precipitation of the trend mode are somewhat similar to those in the ENSO mode, possibly because of the influence of the ocean-atmosphere interaction. 
RMS error in RC23

(a) $850 \mathrm{hPa} \mathrm{u}$
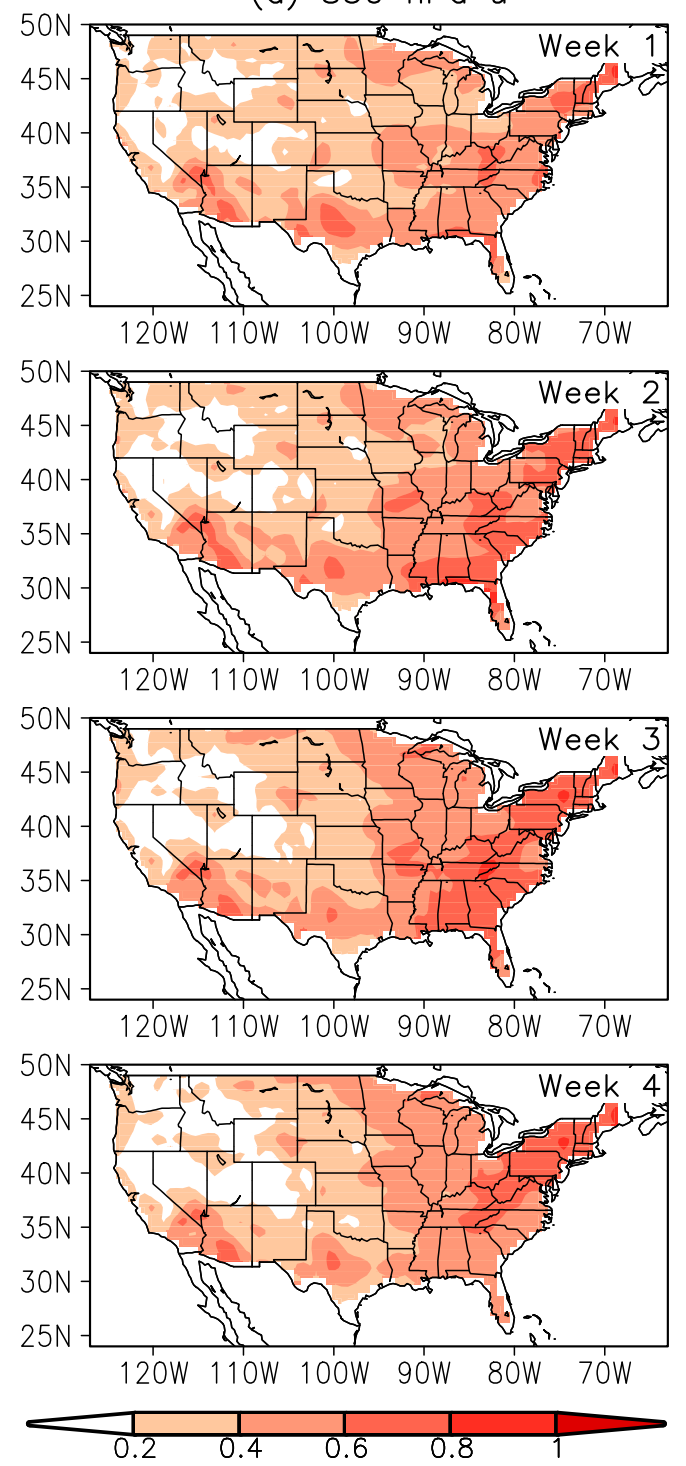

(b) $850 \mathrm{hPa} \mathrm{v}$
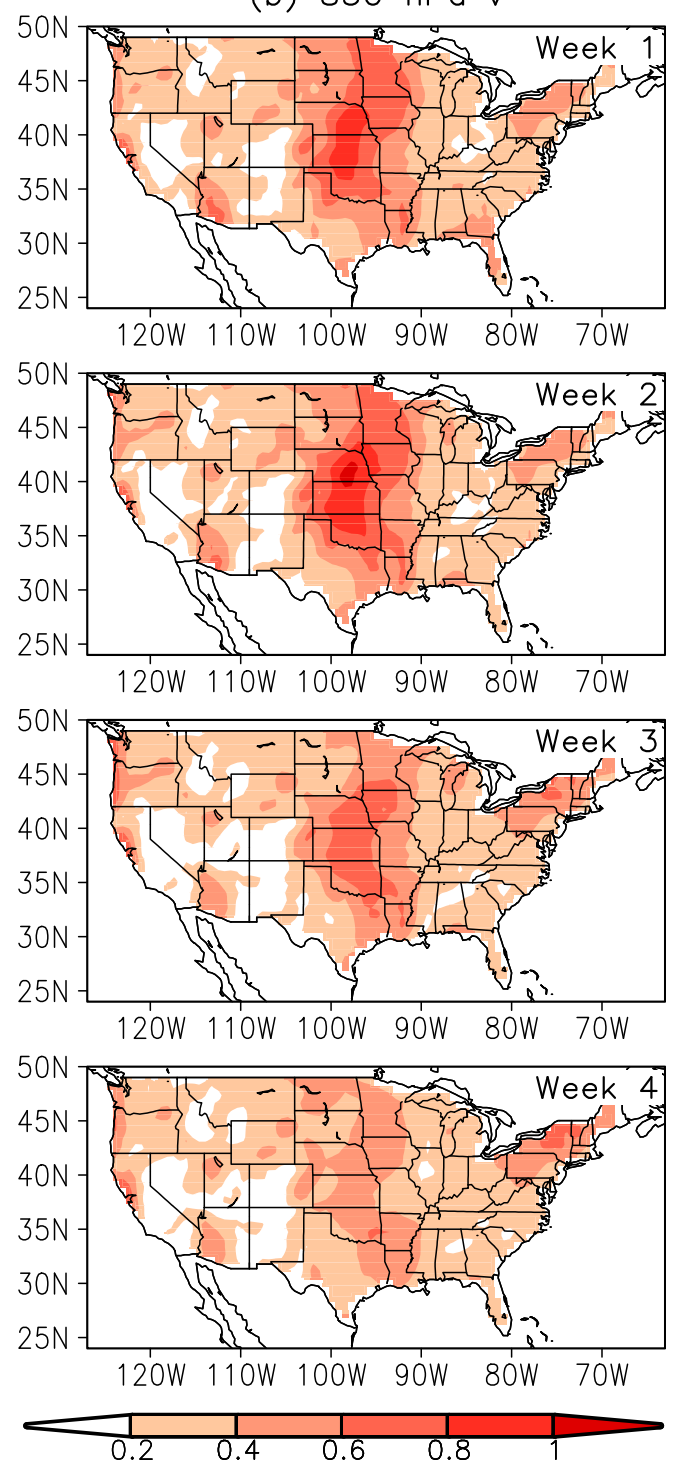

FIG. 13. As in Fig. 11, but for RC23.

\section{b. Spatial correlation}

A further assessment of the model forecasts was carried out through spatial correlation analysis of the $850-\mathrm{hPa}$ horizontal wind, precipitation, and 2-m average temperature. For each variable, the weekly average spatial maps of the 56 forecasts over CONUS during JJAS 2011-17 were strung together as a series separately for weeks $1-4$ of the forecasts. Using a similar series of the spatial maps of the observation over CONUS for the corresponding times, the spatial correlation between the forecasts and observation was computed for weeks 1-4 of the forecasts. The spatial correlations were computed separately for each variable (wind, precipitation, and temperature) and separately for the total anomaly, ENSO mode (RC1), ISO
(RC23), and trend mode (RC4). Further, the correlation was also computed for combined modes (i.e., the sum of RC1, $\mathrm{RC} 23$, and $\mathrm{RC} 4$, referred to as $\mathrm{RC1234}$ ) and the residue (total anomaly minus RC1234). It is difficult to demarcate the correlation value at which the forecasts are skillful. The focus of this study is on determining the relative predictability of the leading modes and to identify the sources of higher predictability. The observed variance of the leading modes, as shown in Fig. S8 for RC1234 of the zonal wind, is also seen in the model although with slightly higher values over the equatorial Pacific.

The spatial correlations for each variable are shown in Fig. 17 for weeks 1-4 forecasts. The correlation of the total anomaly of 850 -hPa zonal wind (Fig. 17a) is about 0.7 in week 1 
RMS error in $\mathrm{RC} 23$

(a) Precipitation
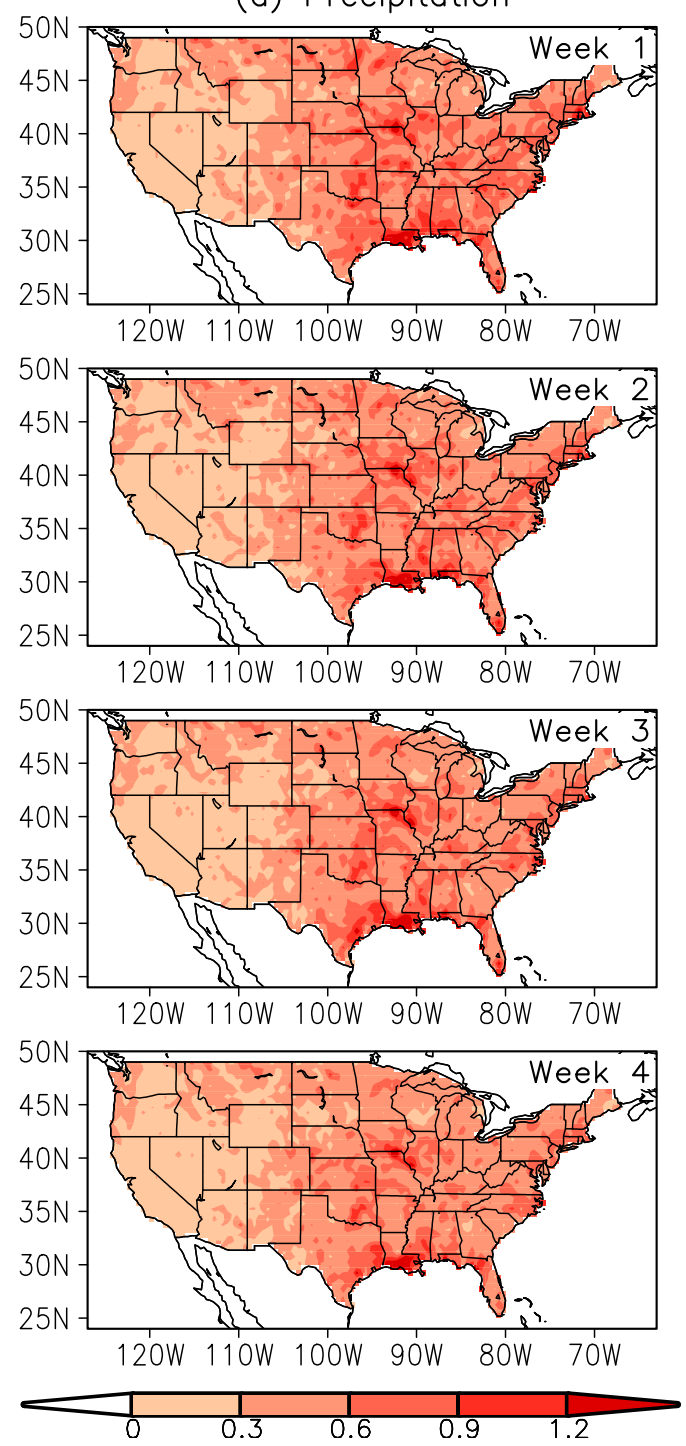

(b) $2 \mathrm{~m}$ Temperature
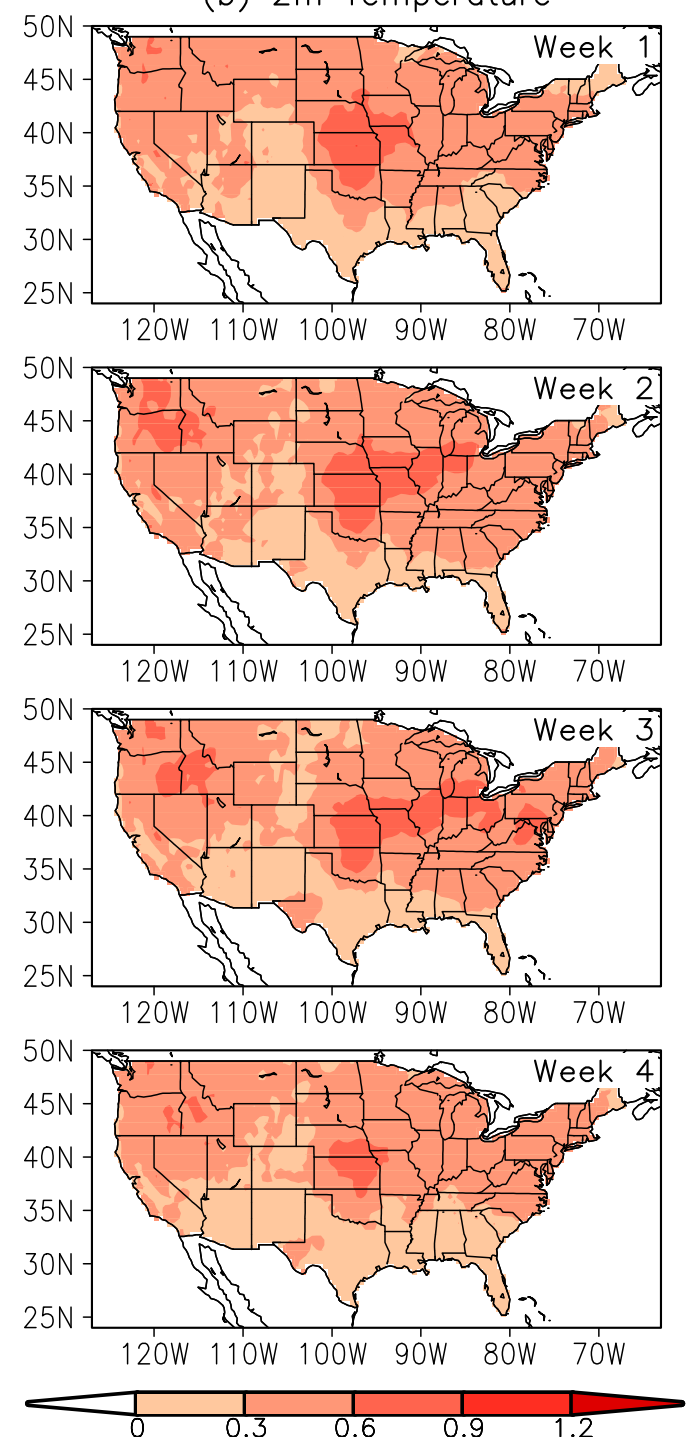

FIG. 14. As in Fig. 12, but for RC23.

but decreases to 0.2 in week 2 and becomes almost zero in week 4. The ENSO mode (RC1) also follows the total anomaly from week 1 to 4 but increases to 0.2 in week 4 . The ISO (RC23) starts with 0.55 in week 1 and maintains moderate correlation at $0.4-0.5$ during weeks $2-4$. The correlation of trend (RC4) is similar to ISO but with slightly lower values going from 0.3 to 0.5 . The combined mode (RC1234) starts with 0.45 in week 1 and has a value around 0.3 for weeks $2-4$. The residue has almost negligible value for all the four weeks. In the $850-\mathrm{hPa}$ meridional wind (Fig. 17b), the total anomaly starts with 0.7 but reaches 0.2 in week 2 and near zero in week 4 . The ENSO mode ( $\mathrm{RC} 1$ ) goes from 0.6 in week 1 to about 0.2 in week 4 while the ISO (RC23) stays in the range of $0.3-0.4$ during weeks $1-4$. The trend (RC4) starts at about 0.35 in week 1 and goes below 0.2 in week 4 . The combined mode (RC1234) varies from 0.4 to 0.2 during weeks $1-4$ while the correlation of the residue is negligible.

The correlation of the precipitation (Fig. 17c) shows the total anomaly and residue both to start at about 0.4 in week 1 and reduce to 0.1 and below during weeks $2-4$. The ENSO mode ( $\mathrm{RC} 1$ ) also follows the total anomaly but within the range of $0.1-0.2$ during weeks $2-4$. The ISO (RC23) remains around 0.35 for all the four weeks while the trend (RC4) goes from 0.35 to 0.15 from week 1 to 4 . The combined mode ( $\mathrm{RC1234}$ ) starts at 0.4 and decreases steadily to 0.2 during the four weeks.

The 2-m average temperature has high values in week 1 for all the components (Fig. 17d). The total anomaly starts close to 0.9 in week 1 but decreases rapidly during weeks $2-4$ and even reaching a small negative value in week 4 . The ENSO mode 
RMS error in RC4

(a) $850 \mathrm{hPa} \mathrm{u}$
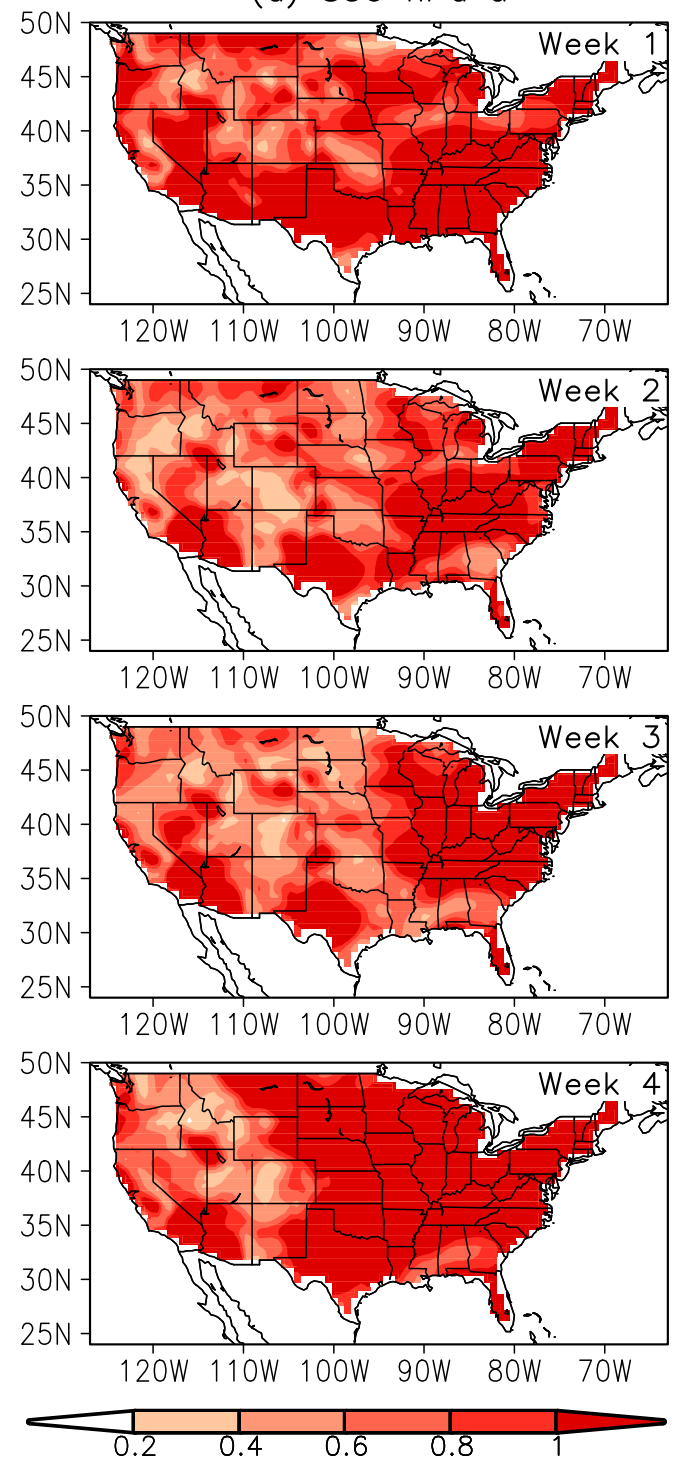

(b) $850 \mathrm{hPa} \mathrm{v}$
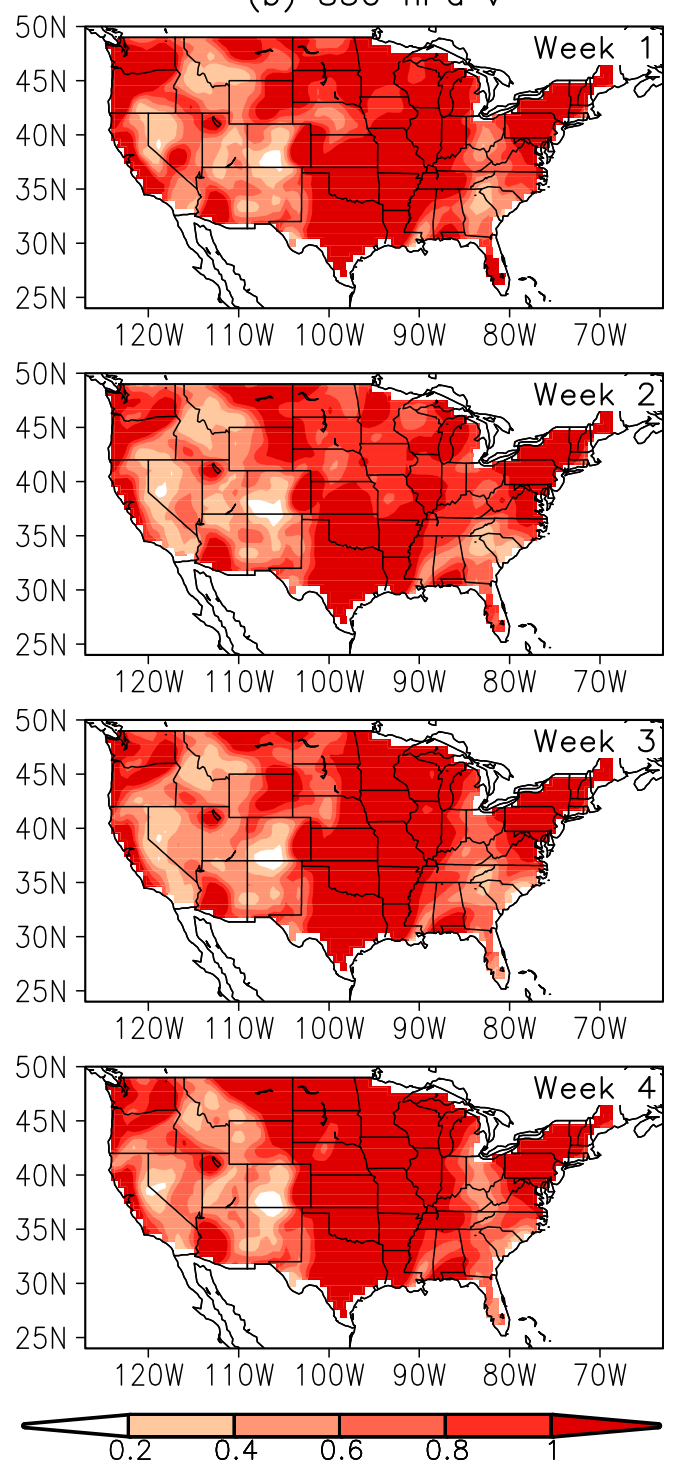

FIG. 15. As in Fig. 11, but for RC4.

(RC1) and the residue follow the total anomaly during weeks $1-3$ but reach 0.1 in week 4 . The ISO (RC23) starts at 0.6 in week 1 and remains around 0.5 during weeks $2-4$. The trend (RC4) had the highest correlation in the range 0.6-0.7 during weeks $2-4$. The combined mode (RC1234) also has high correlation of $0.6-0.7$ during weeks 1 and 2 but reaches moderate values around 0.4 in weeks 3 and 4 .

The correlations of the three leading modes of variability are consistent with the RMS errors of forecasts discussed in the previous subsection. The correlation analysis reveals that the ISO is relatively better predicted in all the fields up to week 4 while the ENSO mode has high correlation only in week 1 . The trend mode comes close to the predictability of the ISO and has the highest predictability in the 2-m temperature. The combined mode ( $\mathrm{RC1234)}$ offers better predictability compared to the total anomaly during all the four weeks. The negligible correlation of the residue indicates that the long-range prediction is better in the leading modes of variability.

\section{Summary and conclusions}

In this study, the reforecasts of the UFS Coupled Model Prototype 2 over the CONUS at weekly time scale were assessed for the boreal summer of the period 2011-17. The retrospective forecasts of the UFS used in this study were generated by the NCEP and consist of 56 sets of month-long predictions during the boreal summer. Since the prediction of instantaneous states beyond the weather time scale of about 
RMS error in RC4

(a) Precipitation
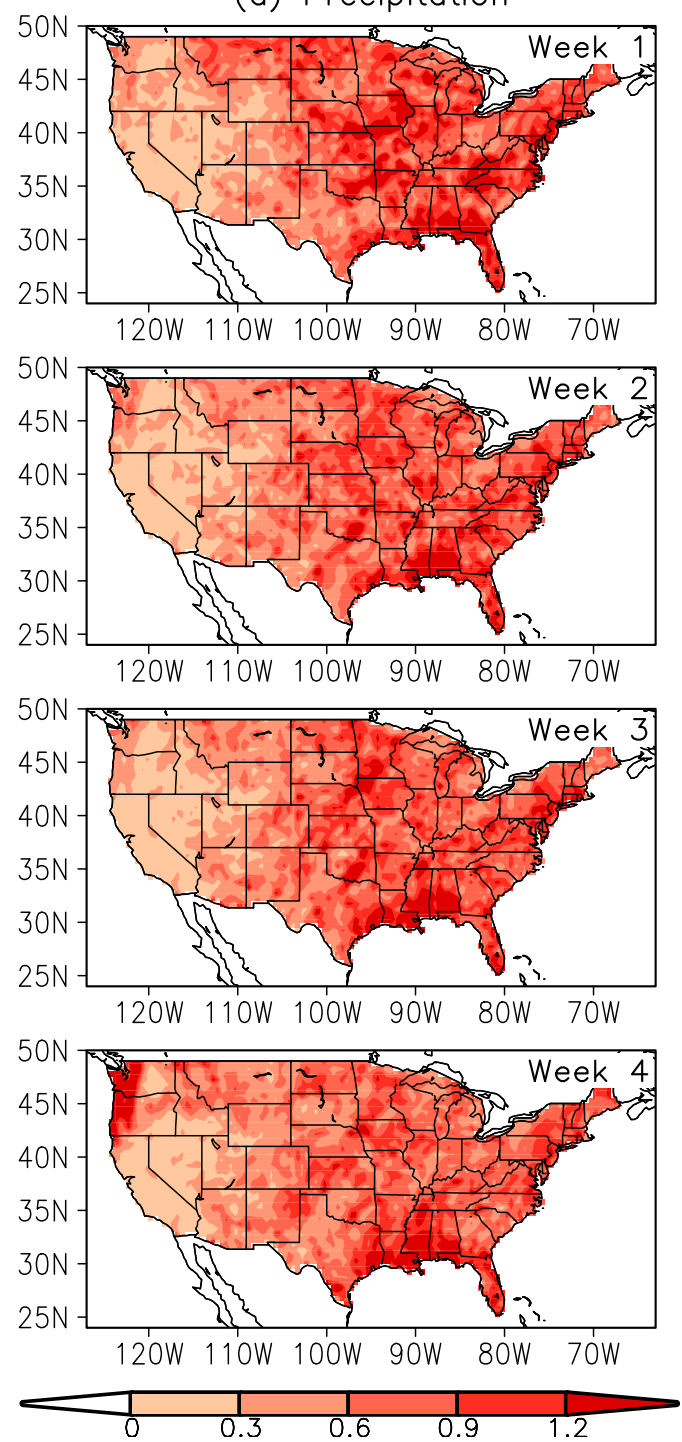

(b) $2 \mathrm{~m}$ Temperature
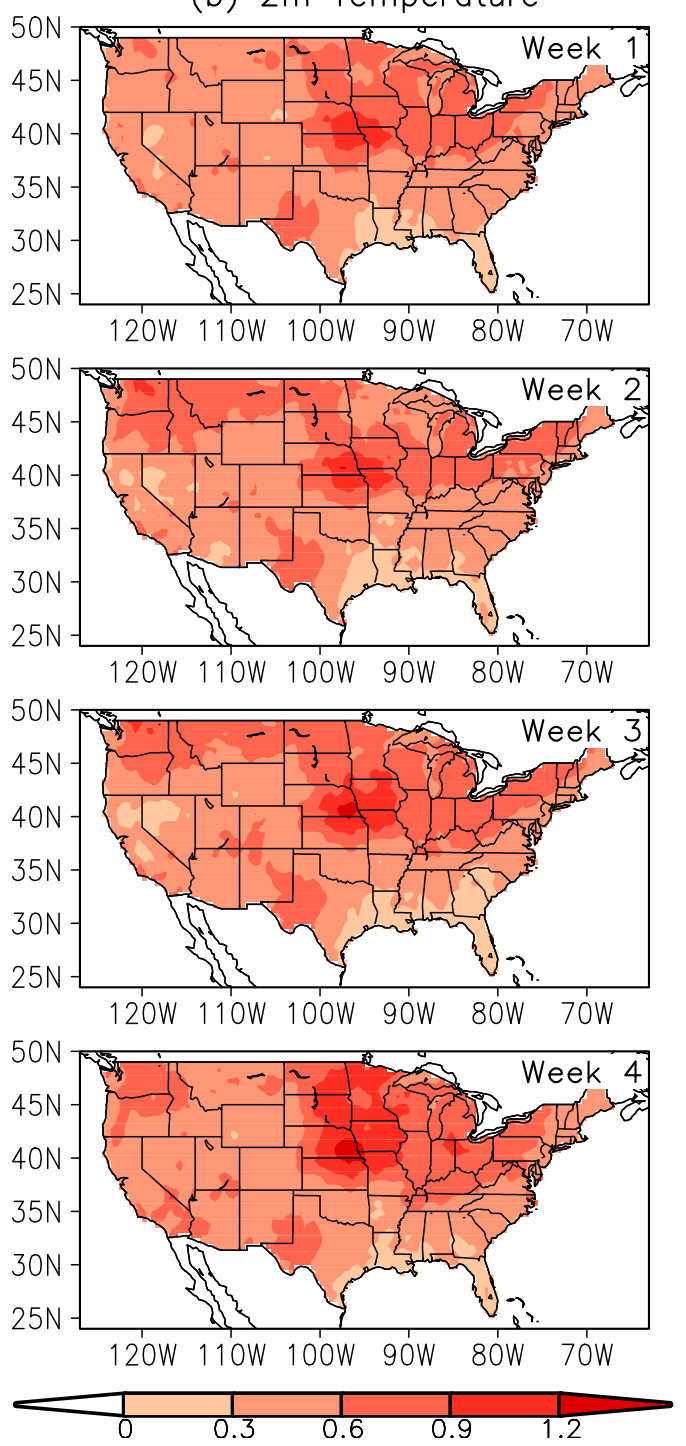

FIG. 16. As in Fig. 12, but for RC4.

10 days is not reliable, the prediction of weekly average in the subseasonal time scale of weeks 1-4 was analyzed. This study has adopted a new approach for climate predictability by decomposing the forecast field into space-time modes using MSSA and then assessing the model's performance in predicting some of the leading modes at subseasonal time scale. The performance of the UFS in capturing the leading modes of variability was examined, and a quantitative analysis of the predictability of these modes was carried out.

The application of MSSA on observed daily 850-hPa horizontal wind over a domain consisting of CONUS and neighboring land and oceanic region yielded three leading space-time eigenmodes. The leading mode is related to ENSO while the second mode is an ISO with an average period of 50 days. The third mode consists of a trend with relation to the warming over the oceans. A projection method using the PCs of the RCs of the observed horizontal wind provided the RCs of horizontal wind in the UFS forecasts as well as the RCs of the precipitation and 2-m average temperature in both observation and forecasts. The UFS forecasts are able to predict the spatial structures of the ENSO mode and ISO in the 850 -hPa horizontal wind, precipitation and 2-m temperature quite well and in the trend mode reasonably well compared to the observational modes. The model is also able to capture the propagation of the ISO and the possible relation with the Indian monsoon.

The RMS errors in the forecasts with respect to observations over the CONUS were analyzed for the total anomalies and the three leading modes. In general, the errors are smaller over the western part and larger over the eastern half of the CONUS in 
(a) $850 \mathrm{hPa} \mathrm{u}$

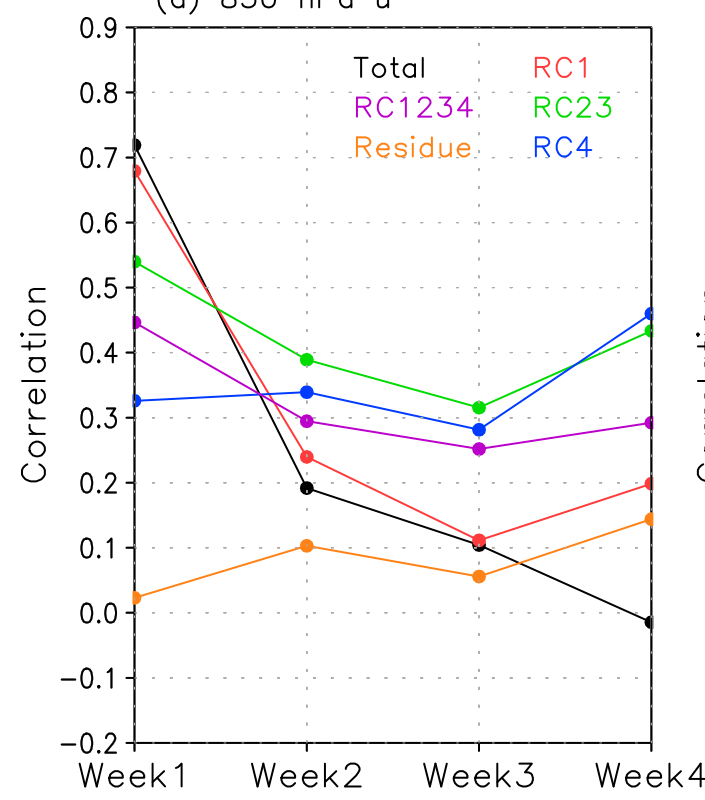

(c) Precipitation

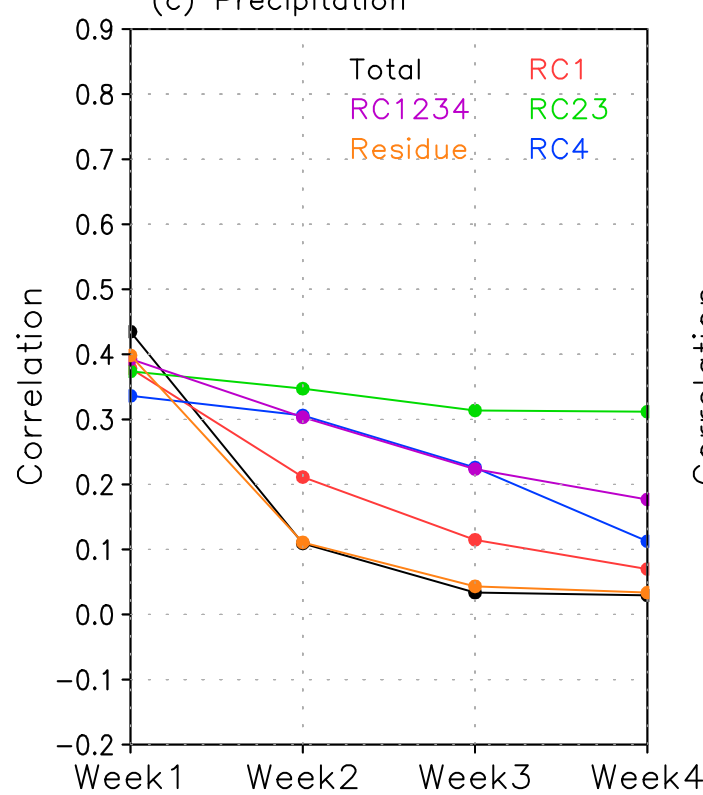

(b) $850 \mathrm{hPa} v$

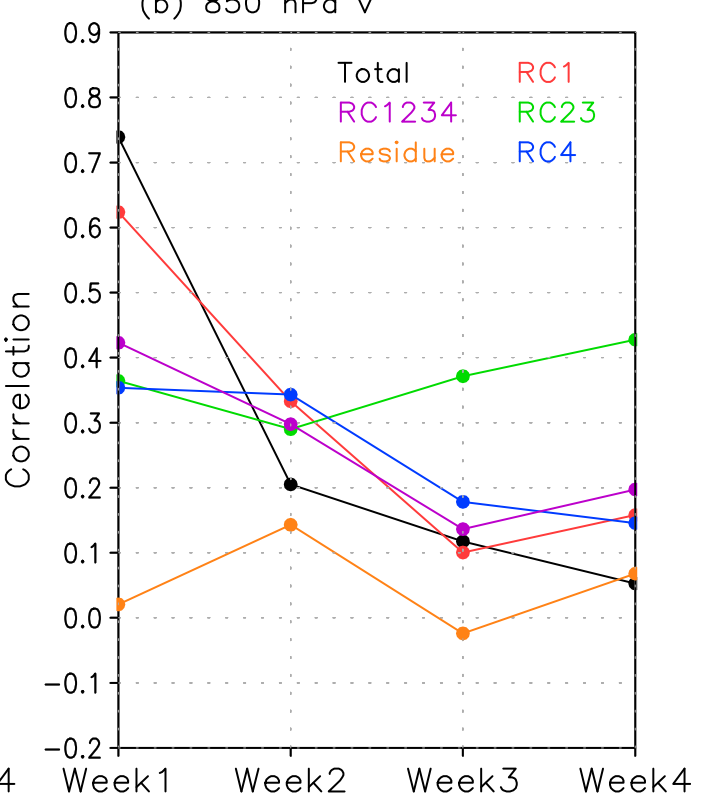

(d) $2 m$ Temperature

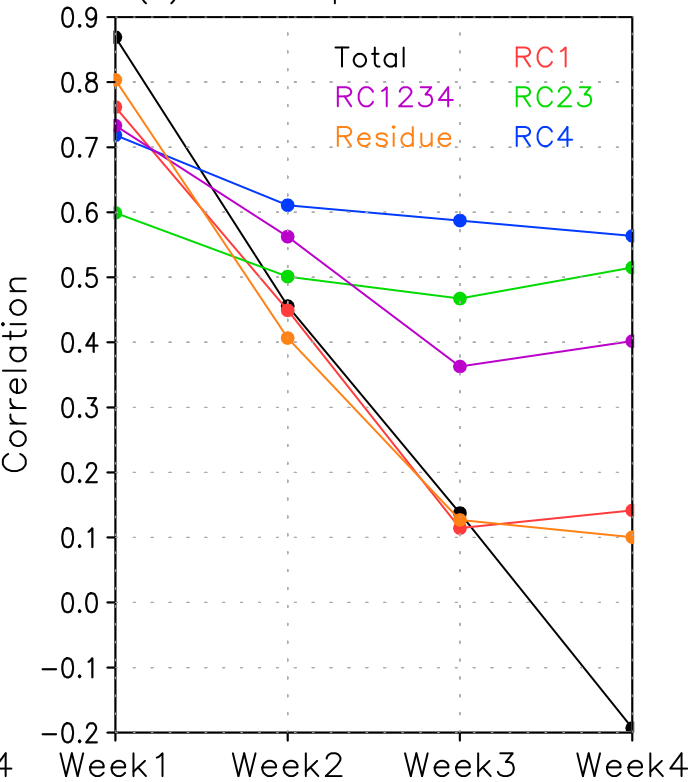

FIG. 17. Spatial correlation of weekly-averaged (a) $850-\mathrm{hPa}$ zonal wind $u$, (b) $850-\mathrm{hPa}$ meridional wind $v$, (c) precipitation, and (d) average 2-m temperature over CONUS between UFS forecasts and observation. The correlations are shown for RC1 (red), RC23 (green), RC4 (blue), RC1234 (purple), residue of RC1234 (orange), and total anomaly (black). The correlation includes all the forecasts during JJAS 2011-17. The observation is from ERA-Interim for winds, $\mathrm{CPCU}$ for precipitation, and $\mathrm{CPC}$ for temperature.

the total anomalies of wind and precipitation and grow from week to week. The errors in temperature are large over most of the CONUS except for the southern coastal region and grow every week. In the ENSO mode, the UFS shows smaller errors over the western half of the CONUS in both the wind and precipitation with very little growth whereas the errors in temperature grow every week and cover a wider area over CONUS with large values. The errors in the ISO are smaller over most of the CONUS with very little weekly growth in wind, precipitation, and temperature. The errors in the trend mode are larger over the eastern part of the CONUS in all the fields, grow from week to week in wind and precipitation, and remain the same in temperature. 
The spatial correlation between the UFS forecasts and observation also revealed the same behavior of the error growth seen in the RMS errors. The correlation of the total anomaly drops to a very low value in the second week itself. In the ENSO mode also, the correlation decreases considerably in the second week but further decrease is slower in weeks 3 and 4 . The correlation in the ISO remains more or less the same with moderate values during all the four weeks. The trend mode also has moderate correlation in wind and precipitation and high values in temperature from week 1 to 4 . The residue after the three leading modes shows negligible correlation in all the weeks.

The analysis of this study has shown that the sources of enhanced predictability at climate time scales can be identified by examining the performance of the model in predicting dynamical modes of variability over the region of interest. The implications of the results of this study are both in the usefulness of the methodology and in the identification of the physical phenomena that provide long-term predictability. The MSSA of the observed circulation provides the space-time structures of the leading modes of variability that are important for the region (CONUS) and season (boreal summer). More importantly, these modes are relevant for examining the predictability beyond the weather time scale, as demonstrated in this study for the subseasonal time scale. Other regions, such as the monsoon systems, have different modes of variability which can be resolved by the MSSA. The EOF projections of the observed MSSA modes provide a convenient method to decompose the forecasts into the corresponding modes and assess the performance of the model. This method is helpful since a direct application of MSSA is not feasible for future forecasts. This study has demonstrated that the EOF projections and the corresponding RCs provide both the assessment of the predictability and the identification of the associated physical phenomena or processes. The specific implications of this method for the present study of predictability over the CONUS during the summer are as follows:

- The UFS seems to have better prediction skill over CONUS at weeks 3-4 in ISO and trend compared to the ENSO mode. The possible reasons for this behavior may lie in the fact that the ISO has more regular cyclic variability and the trend is more persistent.

- The better predictability over the western part of the CONUS in the ENSO mode and ISO may be related to the better performance of the model related to oceanatmosphere interaction in the Pacific. Knowing the predictability of the individual modes is also useful for those locations where the particular mode is of more importance.

- The identification of the sources of different levels of predictability will also be helpful in addressing the problems in modeling.

Acknowledgments. V. Krishnamurthy and C. Stan were supported by the National Oceanic and Atmospheric Administration (Grant NA18NWS4680069). ERA-Interim data can be downloaded from https://www.ecmwf.int/en/forecasts/ datasets/reanalysis-datasets/era-interim.

\section{REFERENCES}

Adcroft, A., and Coauthors, 2019: The GFDL global ocean and sea ice model OM4.0: Model description and simulations features. J. Adv. Model. Earth Syst., 11, 3167-3211, https://doi.org/ 10.1029/2019MS001726.

Allen, M. R., and A. W. Robertson, 1996: Distinguishing modulated oscillations from coloured noise in multivariate datasets. Climate Dyn., 12, 775-784, https://doi.org/10.1007/s003820050142.

— oscillations in the presence of colored noise. J. Climate, $\mathbf{9}$, 3373-3404, https://doi.org/10.1175/1520-0442(1996)009<3373: MCSDIO $>2.0 . \mathrm{CO} ; 2$.

Arcodia, M. C., B. P. Kirtman, and L. S. P. Siqueira, 2020: How MJO teleconnections and ENSO interference impacts U.S. precipitation. J. Climate, 33, 4621-4640, https://doi.org/10.1175/ JCLI-D-19-0448.1.

Charney, J. G., and J. Shukla, 1981: Predictability of monsoons. Monsoon Dynamics, J. Lighthill and R. P. Pearce, Eds., Cambridge University Press, 99-109.

Dee, D. P., and Coauthors, 2011: The ERA-Interim reanalysis: Configuration and performance of the data assimilation system. Quart. J. Roy. Meteor. Soc., 137, 553-597, https://doi.org/ 10.1002/qj.828.

ECMWF, 2018: Annual Report 2017. European Centre for MediumRange Weather Forecast Annual Rep., 40 pp., https://www.ecmwf. int/node/18309.

Ghil, M., and Coauthors, 2002: Advanced spectral methods for climatic time series. Rev. Geophys., 40, 1003, https://doi.org/ 10.1029/2000RG000092.

- A. Groth, D. Kondrashov, and A. W. Robertson, 2018: Extratropical sub-seasonal-to-seasonal oscillations and multiple regimes: The dynamical systems view. Sub-Seasonal to Seasonal Prediction: The Gap between Weather and Climate Forecasting, A. W. Robertson and F. Vitart, Eds., Elsevier, 119-142.

Gottschalck, J., and Coauthors, 2010: A framework for assessing operational Madden-Julian oscillation forecasts-A CLIVAR MJO Working Group project. Bull. Amer. Meteor. Soc., 91, 12471258, https://doi.org/10.1175/2010BAMS2816.1.

Hazra, A., and V. Krishnamurthy, 2015: Space-time structure of diabatic heating in monsoon intraseasonal oscillation. J. Climate, 28, 2234-2255, https://doi.org/10.1175/JCLI-D-14-00280.1.

Huang, B., C.-S. Shin, and A. Kumar, 2019: Predictive skill and predictable patterns of the U.S. seasonal precipitation in CFSv2 reforecasts of 60 years (1958-2017). J. Climate, 32, 8603-8637, https://doi.org/10.1175/JCLI-D-19-0230.1.

Huffman, G. J., and Coauthors, 2001: Global precipitation at onedegree daily resolution from multi-satellite observations. J. Hydrometeor., 2, 36-50, https://doi.org/10.1175/1525-7541(2001) 002<0036:GPAODD > 2.0.CO;2.

Johnson, N. C., D. C. Collins, S. B. Feldstein, M. L. L'Heureux, and E. E. Riddle, 2014: Skillful wintertime North American temperature forecasts out to 4 weeks based on the state of ENSO and the MJO. Wea. Forecasting, 29, 23-38, https://doi.org/ 10.1175/WAF-D-13-00102.1.

Kim, H.-M., P. J. Webster, and J. A. Curry, 2012: Seasonal prediction skill of ECMWF System 4 and NCEP CFSv2 retrospective forecast for the Northern Hemisphere winter. Climate Dyn., 39, 2957-2973, https://doi.org/10.1007/s00382012-1364-6.

Krishnamurthy, V., and J. Shukla, 2007: Intraseasonal and seasonally persisting patterns of Indian monsoon rainfall. J. Climate, 20, 3-20, https://doi.org/10.1175/JCLI3981.1. 
, and _ 2008: Seasonal persistence and propagation of intraseasonal patterns over the Indian monsoon region. Climate Dyn., 30, 353-369, https://doi.org/10.1007/s00382-007-0300-7.

— , and D. Achuthavarier, 2012: Intraseasonal oscillations of the monsoon circulation over South Asia. Climate Dyn., 38, 2335 2353, https://doi.org/10.1007/s00382-011-1153-7.

—, and A. Sharma, 2017: Predictability at intraseasonal time scale. Geophys. Res. Lett., 44, 8530-8537, https://doi.org/ 10.1002/2017GL074984.

Lorenz, E. N., 1965: A study of the predictability of a 28-variable atmospheric model. Tellus, 17, 321-333, https://doi.org/10.3402/ tellusa.v17i3.9076.

_ 1982: Atmospheric predictability experiments with a large numerical model. Tellus, 34, 505-513, https://doi.org/10.3402/ tellusa.v34i6.10836.

_ 1984: Some aspects of atmospheric predictability. Problems and Prospects in Long and Medium Range Weather Forecasting, D. M. Burridge and E. Kallen, Eds., Springer-Verlag, 1-20.

— 2006: Predictability_A problem partly solved. Predictability of Weather and Climate, T. Palmer and R. Hagedorn, Eds., Cambridge University Press, 40-58.

Merryfield, W. J., and Coauthors, 2020: Current and emerging developments in subseasonal to decadal prediction. Bull. Amer. Meteor. Soc., 101, E869-E896, https://doi.org/10.1175/ BAMS-D-19-0037.1.

Moron, V., R. Vautard, and M. Ghil, 1998: Trends, interdecadal and interannual oscillations in global sea-surface temperatures. Climate Dyn., 14, 545-569, https://doi.org/10.1007/ s003820050241.

National Academies of Sciences, Engineering and Medicine, 2016: Next Generation Earth System Prediction: Strategies for Subseasonal to Seasonal Forecasts. The National Academies Press, 350 pp., https://doi.org/10.17226/21873.

Plaut, G., and R. Vautard, 1994: Spells of low-frequency oscillations and weather regimes in the Northern Hemisphere. J. Atmos. Sci., 51, 210-236, https://doi.org/10.1175/1520-0469(1994) $051<0210:$ SOLFOA $>2.0$. CO; 2 .

Reynolds, R. W., T. M. Smith, C. Liu, D. B. Chelton, K. S. Casey, and M. G. Schlax, 2007: Daily high-resolution-blended analyses for sea surface temperature. J. Climate, 20, 5473-5496, https://doi.org/10.1175/2007JCLI1824.1.

Riddle, E. E., M. B. Stoner, N. C. Johnson, M. L. L'Heureux, D. C. Collins, and S. B. Feldstein, 2013: The impact of the MJO on clusters of wintertime circulation anomalies over the North American region. Climate Dyn., 40, 1749-1766, https://doi.org/ 10.1007/s00382-012-1493-y.
Robertson, A. W., and M. Ghil, 1999: Large-scale weather regimes and local climate over the western United States. J. Climate, 12, 1796-1813, https://doi.org/10.1175/1520-0442(1999)012<1796: LSWRAL $>2.0 . \mathrm{CO} ; 2$.

—, and F. Vitart, 2019: Sub-Seasonal to Seasonal Forecasting: The Gap between Weather and Climate Forecasting. Elsevier, $585 \mathrm{pp}$.

—, N. Vigaud, J. Yuan, and M. K. Tippett, 2020: Toward identifying subseasonal forecasts of opportunity using North American weather regimes. Mon. Wea. Rev., 148, 1861-1875, https://doi.org/10.1175/MWR-D-19-0285.1.

Rodney, M., H. Lin, and J. Derome, 2013: Subseasonal prediction of wintertime North American surface air temperature during strong MJO events. Mon. Wea. Rev., 141, 2897-2909, https:// doi.org/10.1175/MWR-D-12-00221.1.

Saha, S., and Coauthors, 2006: The NCEP Climate Forecast System. J. Climate, 19, 3483-3517, https://doi.org/10.1175/ JCLI3812.1.

— , and Coauthors, 2014: The NCEP Climate Forecast System version 2. J. Climate, 27, 2185-2208, https://doi.org/10.1175/ JCLI-D-12-00823.1.

Stan, C., and V. Krishnamurthy, 2019: Intra-seasonal and seasonal variability of the Northern Hemisphere extra-tropics. Climate Dyn., 53, 4821-4839, https://doi.org/10.1007/s00382019-04827-9.

—, D. M. Straus, J. S. Frederiksen, H. Lin, E. D. Maloney, and C. Schumacher, 2017: Review of tropical-extratropical teleconnections on intraseasonal time scales. Rev. Geophys., 55, 902-937, https://doi.org/10.1002/2016RG000538.

Stockdale, T. N., and Coauthors, 2011: ECMWF Seasonal Forecast System 3 and its prediction of sea surface temperature. Climate Dyn., 37, 455-471, https://doi.org/10.1007/s00382-0100947-3.

Vigaud, N., A. W. Robertson, and M. K. Tippett, 2018: Predictability of recurrent weather regimes over North America during winter from submonthly reforecasts. Mon. Wea. Rev., 146, 2559-2577, https://doi.org/10.1175/MWR-D-18-0058.1.

Wheeler, M. C., and H. H. Hendon, 2004: An all-season real-time multivariate MJO index: Development of an index for monitoring and prediction. Mon. Wea. Rev., 132, 1917-1932, https:// doi.org/10.1175/1520-0493(2004)132<1917:AARMMI>2.0. $\mathrm{CO} ; 2$.

Xie, P., M. Chen, and W. Shi, 2010: CPC unified gauge-based analysis of global daily precipitation. 24th Conf. on Hydrology, Atlanta, GA, Amer. Meteor. Soc., 2.3A, https://ams.confex.com/ams/ 90annual/techprogram/paper_163676.htm. 